\title{
Agentes da tradução e circulação dos clássicos na periferia da ciência
}

O caso da revista brasileira GEOgraphia (1999-2019)

Agents of translation and circulation of classics at the scientific periphery: the case of Brazilian journal GEOgraphia (1999-2019)

Les agents de la traduction et la circulation des classiques dans la périphérie de la science : le cas de la revue brésilienne GEOgraphia (1999-2019)

Los agentes de la traducción y la circulación de los clásicos en la periferia de la ciencia: el caso de la revista brasileña GEOgraphia (1999-2019)

\section{Guilherme Ribeiro}

\section{OpenEdition}

Journals

\section{Edição electrónica}

URL: https://journals.openedition.org/terrabrasilis/8014

DOI: 10.4000/terrabrasilis.8014

ISSN: 2316-7793

Editora

Rede Brasileira de História da Geografia e Geografia Histórica

\section{Refêrencia eletrónica}

Guilherme Ribeiro, "Agentes da tradução e circulação dos clássicos na periferia da ciência», Terra Brasilis [Online], 15 | 2021, posto online no dia 31 julho 2021, consultado o 05 dezembro 2022. URL: http://journals.openedition.org/terrabrasilis/8014 ; DOI: https://doi.org/10.4000/terrabrasilis.8014

Este documento foi criado de forma automática no dia 5 dezembro 2022.

All rights reserved 


\section{Agentes da tradução e circulação dos clássicos na periferia da ciência}

O caso da revista brasileira GEOgraphia (1999-2019)

Agents of translation and circulation of classics at the scientific periphery: the case of Brazilian journal GEOgraphia (1999-2019)

Les agents de la traduction et la circulation des classiques dans la périphérie de la science : le cas de la revue brésilienne GEOgraphia (1999-2019)

Los agentes de la traducción y la circulación de los clásicos en la periferia de la ciencia: el caso de la revista brasileña GEOgraphia (1999-2019)

\section{Guilherme Ribeiro}

\section{NOTA DO AUTOR}

Redigido originalmente em inglês, a versão em português foi traduzida pelo próprio Guilherme Ribeiro. Archie Davies e Laura Péaud fizeram críticas substanciais a esse artigo contribuindo sobremaneira para seu aperfeiçoamento, Leonardo Arantes e Breno Viotto Pedrosa gentilmente esclareceram várias questões relativas às suas formações institucionais e traduções e Eustógio Dantas forneceu-me informação preciosa sobre a expansão da pós-graduação em geografia no Brasil. Esse texto integra nosso projeto "Centro de cálculo, redes de circulação e história da geografia: o caso da Revista Brasileira de Geografia do IBGE (1939-1996)", contemplado pelo edital Faperj Apoio a Grupos Emergentes de Pesquisa no Estado do Rio de Janeiro em 2019.

\section{Introdução}

1 O artigo em tela integra um projeto de investigação sobre as traduções publicadas por quatro periódicos brasileiros de 1939 a 2019: Revista Brasileira de Geografia, Boletim Geográfico, Espaço e Cultura e GEOgraphia. Enquanto os dois primeiros foram editados por 
um dos mais importantes "centros de cálculo" (Latour, 1987) da América Latina, o Instituto Brasileiro de Geografia e Estatística (IBGE) - um dos símbolos do pioneirismo e da consolidação da geografia na periferia da ciência ao longo do século passado -, os outros dois surgiram graças ao desenvolvimento dos cursos de mestrado e doutorado abertos na virada do século vinte para o século vinte e um. Comparando-os e distinguindo-os segundo contextos intelectuais, históricos e geopolíticos, nosso objetivo é o de pesquisar o papel dos tradutores e das traduções na circulação das ideias estrangeiras no Brasil.

2 Por aqui, tradução pode ser considerada, em termos braudelianos (Braudel, 1997), uma prática de longa duração. No período colonial, portugueses deportados e marinheiros desertados eram deixados entre os indígenas para aprender suas línguas e, por esta razão, eram chamados exatamente de "línguas" (Gonçalves Barbosa e Wyler 2001: 326 [1998]). Na primeira metade do século dezenove, no intuito de participar do mundo civilizado a atração brasileira pela atmosfera europeia levou à tradução da Revue Brittanique. Porém, ela era traduzida não a partir do original em inglês, mas de sua versão francesa (Ramicelli, 2009). No início do século vinte, o periódico médico nacional Memórias do Instituto Oswaldo Cruz tinha que publicar artigos em alemão e em francês se quisesse alcançar a comunidade "internacional", muito embora os autores fossem brasileiros (Hanes, 2014). De 1939 a 1957, os artigos editados pela Revista Brasileira de Geografia eram acompanhados por resumos em francês, inglês, espanhol, alemão, italiano e mesmo esperanto, e qual não foi nossa surpresa ao constatar que entre $1943 \mathrm{e}$ 1978 o Boletim Geográfico traduziu quase quatrocentos e cinquenta artigos para o português, tornando-se provavelmente um dos periódicos que mais investiu nesse gênero de circulação e escrita em todo o mundo (Ribeiro, 2018).

Um dos mais novos capítulos dessa tradição - expressa inclusive teoricamente, tal como demonstram os conceitos de antropofagia elaborado pelo modernista Oswald de Andrade em 1920 e transcriação cunhado pelo poeta e tradutor concretista Haroldo de Campos nos anos de 1960 (de Andrade, 2017 [1928]; de Campos, 2006 [1963]) - têm sido redigido nas páginas da GEOgraphia. Fundada em 1999 pelo Departamento de Geografia da Universidade Federal Fluminense (UFF) na cidade de Niterói, Estado do Rio de Janeiro, ela seria mais uma revista comum se não fosse a seção Nossos Clássicos. Dedicada às traduções e aos comentários realizados pelos próprios tradutores, não demorou muito para que ela se tornasse uma rica fonte para todos os interessados em história da geografia, ${ }^{1}$ atraindo quer nossos vizinhos argentinos (Lus Bietti, 2019), quer europeus progressistas em busca de "outras tradições geográficas" (Ferretti, 2019 :8-9). Além disso, recentemente outras publicações nacionais como Terra Brasilis e Tamoios buscaram inspiração na GEOgraphia para se dedicarem à tradução e ao debate em torno dos clássicos.

4 Buscando apreender a história da geografia brasileira enfatizando as relações entre língua e política, o presente artigo visa a conhecer quem são os autores traduzidos, quem os traduziu e por quais razões o fizeram. Baseado na articulação entre o pensamento decolonial e os translation studies, nosso principal argumento opera em duas frentes. Em linhas gerais, explora os vínculos entre a condição periférica de um país como o Brasil e o ato de traduzir. Afinal, nações centrais e suas línguas dominantes não são obrigadas a recorrer ao bilinguismo ou ao multilinguismo (Casanova, 2015). Assim, as línguas têm tido papel crucial tanto na colonização da memória e do imaginário quanto nas assimétricas trocas intelectuais operadas no âmbito da divisão 
internacional do trabalho intelectual (Anzaldúa, 1981, 1987; Mignolo, 1995, 2012). Do ponto de vista particular, as traduções dos clássicos publicada pela GEOgraphia têm sido uma forma de repensar questões "canônicas" (Keighren et al., 2012) ao redor da história da geografia engendradas tanto na escala nacional quanto na internacional. Algumas dessas questões - a dicotomia Ratzel determinista e Vidal de la Blache possibilista, para citar apenas uma delas - têm sido amplamente difundidas por meio de livros como Introdução à geografia: geografia e ideologia (Sodré, 1976), o que é Geografia? (Moreira, 1980), Geografia: pequena história crítica (Moraes, 1999 [1981]) e Geografia, ciência da sociedade: uma introdução à análise do pensamento geográfico (Andrade, 1987), mas também por A terra e a evolução humana. Introdução geográfica à história (Febvre, 1991 [1922]) e A geografia - isso serve, em primeiro lugar, para fazer a guerra (Lacoste, 1988 [1976]).

5 Em suma, traduções reproduzem, mas também questionam narrativas dominantes (Spivak, 2010). De toda maneira, não existem traduções sem tradutores. Esta, porém, não é uma constatação tão óbvia, pois historicamente tradutores têm sido negligenciados das mais diferentes formas (Schulte, 1992; Venuti, 1995, 1998). A nosso ver, tais negligências podem ser interpretadas como se o trabalho do tradutor precisasse estar, de certa forma, sob constante suspeita e vigilância. Para reverter essa situação, é preciso chamar atenção para o papel e a agência dos tradutores (Buzelin 2005, 2010, Sakai 2010). Ou, se nos for permitido, do que denominaremos geotradutores, visando com isto sublinhar que o tráfego científico internacional, ao admitir toda uma geografia ao redor de artigos, capítulos, revistas, prefácios e afins, tem nos tradutores agentes primordiais. $\mathrm{O}$ produto final de seu trabalho, a tradução, é apenas a ponta de um iceberg cuja dimensão permanece todavia oculta. Entretanto, até chegar ao leitor final a tradução evoca uma ampla rede passando pela formação idiomática do tradutor, pelo diálogo estabelecido com interlocutores nacionais ou estrangeiros, por negociações e pagamentos de direitos editoriais mas, principalmente, pelos processos de seleção (e, inevitavelmente, de exclusão [cf. Foucault, 1971/1970]) de autores, conceitos e métodos. Enfim, da materialidade à intelectualidade inscritas na circulação científica, é preciso fazer valer a espacialidade e a atuação dos tradutores. Para isto, talvez o conceito de geotradutor aqui esboçado possa vir a ter alguma utilidade.

6 Esse trabalho está dividido em quatro partes. A primeira aproxima pensamento decolonial e translation studies a fim de conceber as traduções como objetos geográficos e geopolíticos, além de tomá-las como rastros formativos da circulação científica. A segunda examina as traduções e seus respectivos comentários visando relacionar agentes e intenções. A conclusão acentua como a seção Nossos Clássicos tornou-se importante fórum de debates sobre histórias canônicas da geografia no Brasil e no mundo por meio das traduções graças à intervenção dos geotradutores.

\section{Tradução como objeto geográfico e geopolítico: perspectivas metodológicas}

7 É quase impossível pensar a vida intelectual brasileira sem referências estrangeiras - e, portanto, sem traduções. Entretanto, ousaríamos dizer que essa presença é tão familiar que se tornou natural. Esta, porém, é uma situação insólita principalmente em termos geográficos, pois a dimensão espacial da tradução, a circulação, faz (ou deveria fazer) com que estas duas palavras sejam praticamente sinônimas. Portanto, é difícil conceber 
os motivos pelas quais ambas têm sido ignoradas como temas geográficos no transcorrer do século vinte.

8 Por outro lado, cumpre notar que os translation studies têm frequente recorrido à expertise geográfica - notadamente às contribuições associadas ao spatial turn (Bachmann-Medick, 2016 [2015]) - a fim de estudar o papel teórico do espaço na compreensão das traduções; pesquisar como as traduções podem afetar o imaginário sobre os lugares; entender os aspectos ideológicos das traduções em tempos de guerra; e iluminar o movimento e a dinâmica das traduções em um mundo globalizado. 0 resultado da fusão entre translation studies e spatial turn pode ser exemplificado por conceitos como "paradigm of space", "translating geographies", "geographies of translation" (Italiano, 2012, 2016), "translational spaces" (Bachmann-Medick, 2009), "translation zone", "Balkan Babel" (Apter, 2006) e "new geography of translation" (Cronin, 2003).

9 Da posição de geógrafo, nossa leitura dos translation studies articula três direções: na primeira, traduções têm uma natureza particular seja como tema intelectual, seja como objeto híbrido do ponto de vista textual. Contudo, o entendimento das traduções é tão precário que Venuti se viu obrigado a redigir algumas orientações sobre "como ler uma tradução" (Venuti, 2004. See also Venuti, 2009, 2013), enquanto Apter alça a tradução ao status de uma nova literatura comparada (Apter, 2006). Na segunda direção, traduções podem ser compreendidas como uma forma de método apta a iluminar a seleção dos geógrafos estrangeiros promovidas pelos brasileiros. Através das traduções é possível identificar uma frondosa rede contendo laboratórios, revistas e viagens, de um lado, e influências internacionais, hierarquias científicas e políticas editoriais, de outro. No interior dessa rede o espaço tem tido papel central, tal como Rupke bem soube resumir:

Um estudo detalhado e sistemático de traduções deve mostrar-se altamente eficiente como ferramenta de análise do conhecimento científico em termos de região e de território (...) e da cartografia da compreensão científica (...) Estudos sobre tradução podem ajudar a responder duas questões formuladas por Shapin: como a ciência se desloca com uma eficiência tão notável (...) e até que ponto as circunstâncias locais estão envolvidas nos significados que os textos científicos adquirem e nas intenções as quais eles servem? (Rupke, 2000: 210, tradução nossa)

10 A terceira direção aponta para o fato de que as traduções precisam ser desnaturalizadas. Como objetos geográficos, elas não são transportadas por uma entidade metafísica e seus conteúdos tampouco foram selecionados ao acaso ou são independentes do lugar e da língua. Tradução é ação (Buzelin, 2005, 2010), e um tipo de ação geopolítica (Tymoczko, 2000; Spivak, 2010; Mezzadra e Neilson, 2013; Mezzadra e Sakai, 2014; Casanova, 2015). Portanto, tradutores não podem permanecer invisibilizados (Venuti, 1995, 1998). Mais que atos individuais aleatoriamente disseminados em revistas e livros, traduzir é um movimento social submetido a conjunturas históricas, orientações ideológicas e políticas institucionais as quais têm governado a produção do conhecimento. Muito além de neutras ou passivas, traduções estão presentes tanto nos "modernos regimes de tradução" responsáveis por moldar as línguas nacionais (Sakai, 1992, 1997) quanto em discursos e práticas territoriais mobilizados pelas "Escolas Nacionais de Geografia".

11 Nos últimos anos, alguns poucos geógrafos brasileiros têm atentado para o poder da língua e da tradução, tal como observamos na interrogação de Novaes sobre até que ponto a International Conference of Historical Geographers pode ser considerada realmente 
internacional (Novaes, 2015); no texto mais específico For a critical practice of translation in geography co-assinado por Husseini de Araújo (Germes e Husseini de Araújo, 2016); no artigo $O$ papel ativo da geografia: um manifesto e no livro Por uma outra globalização: do pensamento único à consciência universal, ambos de Milton Santos vertidos para o inglês por Tim Clarke e por Lucas Melgaço (o primeiro é acompanhado de um texto assinado por Melgaço cuja mensagem é mais que direta: é preciso "pensar fora da bolha do Norte Global" [Melgaço, 2017]); e no capítulo sobre multilinguismo no congresso internacional da UGI no Rio de Janeiro em 1956 (Lamego, 2020).

Publicados por importantes veículos tais como o Journal of Historical Geography, ACME, Antipode e a editora Springer, infelizmente eles são a regra que comprova a exceção; não por acaso, foram escritos em inglês e dedicados a uma audiência anglófona - ainda que por razões críticas, inútil esclarecer. A nosso juízo, tradução e língua têm sido assimiladas pela maioria dos geógrafos brasileiros como uma questão "cultural" no sentido ingênuo e despolitizado do termo, com a cultura parecendo autonomizar as "Letras" da história e da sociedade e, assim, dissipando o poder e a geopolítica dos processos e agentes responsáveis por conformar uma geografia "internacional" da ciência, dos livros, da leitura e das traduções recheada de tensões e desigualdades - algo que nem sempre a bibliografia em língua inglesa debruçada sobre temas que circulam apenas em espaços anglo-saxões falantes de inglês consegue alcançar (Livingstone, 2003, 2005; Naylor, 2005, 2005a). Como resultado dessa atitude por parte dos geógrafos brasileiros, a francofonia, estrutura constitutiva da geografia universitária no país, torna-se apenas uma tradição intelectual e não o resultado de negociações entre centros e periferias, por exemplo. Tal atitude também pode ajudar a explicar porque os inflamados debates sobre a hegemonia da língua inglesa envolvendo geógrafos de diferentes partes do mundo não teve eco no Brasil (Minca, 2000; Desbiens, 2002; GarciaRamon, 2003; Aalbers, 2004; Desbiens e Ruddick, 2006). Nessa linha de raciocínio, será que o desinteresse dos geógrafos brasileiros de publicar em inglês não está relacionado à sua incompreensão mais ampla diante das línguas como fenômenos socioespaciais? A situação torna-se ainda mais complexa pelo fato de que geógrafos brasileiros continuam traduzindo muito mas, contraditoriamente, não têm tido consciência suficiente - incluindo o autor dessas linhas, grife-se - de que é exatamente a condição periférica que lhes impele a realizar esse tipo de trabalho. Destarte, a tradução continua sendo representada como um obstáculo linguístico stricto sensu a ser resolvido e não como um tópico a ser estudado.

Do iluminismo francês a conformar a modernidade ao american way of life estadunidense difundido após a II Guerra Mundial, a língua nunca foi um "soft power" (Nye, 2004), e é difícil imaginar como conceito tão precário tenha sido levado a sério. De toda maneira, ao invés de considerá-lo apenas do ponto de vista ideológico, cremos que ele revela a dificuldade de incorporar a língua ao modus operandi da ciência geográfica. Ao conceber a língua como um regulador do que lemos, ensinamos e escrevemos, estaremos mais atentos aos aspectos sociais, éticos e geopolíticos que têm norteado a produção do conhecimento e os intercâmbios intelectuais entre centros e periferias - incluindo, decerto, as traduções (Spivak, 2000). Embora cientes das limitações do modelo binário centro-periferia (Raj, 2013), nem por isso deixamos de estar convencidos de que o mundo científico opera em uma balança desigual de fluxos, influências e legitimidade para não mencionar preconceitos e afins. Por isto, acentuaremos que a circulação dos clássicos europeus na periferia via traduções não é um deslocamento aleatório (vide Bourdieu, 2002 [1990]). Ela obedece a uma geopolítica do conhecimento de longa 
duração no interior da qual a tradução é um gênero de dominação de uma língua por outra (Mignolo, 2000; Casanova, 2015). A língua e sua irmã gêmea, a tradução, têm moldado o pensamento e a produção de saber no âmago da modernidade/colonialidade. Deste ponto de vista, a epistemologia euro-ocidental dominante não pode ser examinada sem uma crítica à linguagem em geral (Mignolo, 1995; Kilomba, 2008; Mbembe, 2013) - o que abre caminho, inclusive, para a possibilidade de desenvolver uma "tradução decolonial" (Mignolo, 2012: 33). Nas palavras de Mignolo:

Basicamente, o direcionamento da tradução começa a mudar graças ao crescente número de estudantes do Terceiro Mundo que se tornam acadêmicos e cientistas no Primeiro Mundo. Aqui, o problema da tradução não é um problema de língua, mas um problema do intelectual. 0 racismo opera por meio da linguagem e a diferença colonial não têm sido esquecida, pois um cientista proveniente do Terceiro Mundo carrega consigo os traços do seu próprio "pecado". A saber, o pertencimento à fração da população historicamente desprovida [deficient] em termos epistemológicos e ontológicos. Sempre existem exceções, mas a regra das diferenciações coloniais ainda permanece. (Mignolo 2012: 27, tradução nossa)

Assim, inspirado pelas ideias expostas até aqui, acentuando tanto a agência dos tradutores quanto a espacialidade inerente à tradução, passaremos a defini-los como geotradutores, pois suas iniciativas são atos sociais e, como tais, configuram toda uma geografia de idiomas, periódicos e métodos que, deliberadamente selecionadas porém condicionadas por estruturas históricas e políticas cujas consequências são sentidas em nossos dias, conformam no decorrer do tempo uma paisagem intelectual na qual determinados marcadores (textos, conceitos e autores) aparecem com mais ou menos frequência, forjando certas tradições em detrimento de outras. Para além de mediadores culturais, geotradutores são agentes que, ao difundirem valores, influências e visões de mundo, mobilizam a dimensão política das línguas ao reproduzirem as assimétricas relações de poder entre as nações no âmbito da produção do conhecimento científico.

\section{Línguas, tradutores e redes em ação: da formação à consolidação da Nossos Clássicos (1999-2019)}

15 Enquanto vários cursos de graduação em geografia foram progressivamente abertos em diversas regiões brasileiras no decorrer do século vinte, apenas cinco universidades estavam aptas a oferecer cursos de mestrado em geografia (UFRJ, UFMG, UFPE, UFSE e UFSC) e apenas duas de mestrado e doutorado (USP e UNESP-Rio Claro). Todavia, o baixo número de cursos de pós-graduação e a concentração espacial no core do país (Região Sudeste) começaram a mudar nos anos de 1990 e na primeira década do corrente século (Dantas, Augustin e Cavalcanti, 2016). Não obstante a implementação de políticas educacionais neoliberais durante os governos de Fernando Henrique Cardoso (1995-2002) - cujos impactos negativos foram parcialmente revertidos nos anos seguintes graças à criação de cursos, institutos federais e universidades promovidos pelos governos Lula (2003-2010) no âmbito do REUNI -, a estratégia de sobrevivência das universidades consistiu em fundar cursos de pós-graduação e suas respectivas revistas. Muito mais que uma dinâmica intelectual, estamos diante de um processo nacional de resistência política e institucional contra o neoliberalismo. ${ }^{2}$

Neste contexto, três recém-criados periódicos de geografia circulavam no Rio de Janeiro nos anos noventa: Espaço e Cultura, veículo pioneiro inaugurado em 1995 pelo 
Núcleo de Estudos e Pesquisas sobre Espaço e Cultura (NEPEC) liderado por Zeny Rosendhal e Roberto Lobato Corrêa no Departamento de Geografia da UERJ; GeoUERJ, publicada desde 1997 pelo Departamento de Geografia da UERJ; e a Território, publicada a partir de 1996 sob responsabilidade do Laboratório de Gestão do Território (LAGET), associado ao prestigioso Departamento de Geografia da UFRJ. Apenas a última encerrou suas atividades. Entre sobrevivência e concorrência, a UFF, cuja graduação em geografia data de 1947, abriu seus cursos de mestrado e doutorado em geografia em 1998 e 2001 respectivamente, bem como sua revista, a GEOgraphia, em 1999. Entre seus fundadores estavam profissionais reconhecidos e em ascensão, bem como dois representantes históricos da Geografia Crítica no Brasil: Ruy Moreira, reconhecido por articular marxismo e geografia sob a ótica epistemológica, e Carlos Walter PortoGonçalves, celebrado por seus trabalhos envolvendo capitalismo, movimentos sociais rurais e ambientalismo (Moreira, 2007; Porto-Gonçalves, 2006).

Em seu número inaugural, GEOgraphia publicou a conferência de abertura de seu programa de pós-graduação a cargo de Milton Santos (Santos, 1999). Para um programa recém-lançado, não deixava de ser uma forma de prestígio. Os demais artigos eram assinados pelos próprios professores da casa - algo comum à época, registre-se. Entre editoriais, artigos, resenhas e indicações de livros acompanhadas de pequeno parágrafo-síntese e da reprodução dos sumários, GEOgraphia não teria nada de diferente não fosse pela rubrica Nossos Clássicos. Ao lado do comitê editorial e outros elementos informativos, ela foi assim descrita em uma pequena nota de apresentação à nova revista: "Uma sessão [sic] permanente será dedicada aos clássicos, visando resgatar e estimular a leitura e o debate de suas obras através de textos selecionados, visando trazer para o âmbito da geografia um hábito de há muito corrente nas demais áreas acadêmicas" (p. 2). Acrescente-se aqui uma informação que fará toda a diferença: quase todas as traduções seriam acompanhadas de textos críticos assinados pelos próprios tradutores.

18 Todas as revistas têm sua história e, nos primeiros anos, é notório o esforço de atrair leitores e bons artigos, bem como o de superar as dificuldades inerentes a cada nova edição. Assim, optamos por dividir essa parte do artigo em dois blocos de dez anos cada, pois cremos que a comparação entre as duas décadas servirá para distinguir movimentos superficiais e gerais e, no final, extrair a dinâmica das traduções acionada pela Nossos Clássicos.

\section{Os anos iniciais ou Testando uma fórmula (1999-2009)}

19 De periodicidade semestral, de 1999 a 2009 a seção Nossos Clássicos lançou 22 números, 20 traduções extraídas de 14 diferentes fontes, 19 comentários, 11 tradutores, 11 autores traduzidos de 3 nacionalidades (francesa, alemã e norte-americana) e de 4 idiomas (francês, alemão, espanhol e inglês). As principais fontes, autores traduzidos e tradutores são os Annales de Géographie [5 vezes], Vidal de la Blache [8] e Rogério Haesbaert [5], respectivamente. Autores franceses aparecem 13 vezes (Vidal [8], Reclus [2], Tricart [1], Sorre [1] e Dresch [1]), alemães 6 vezes (Kant [2], Hettner [1], Humboldt [1], Ratzel [1] e Benjamin [1]) e norte-americanos 1 única vez (Sauer). 
20 Em termos qualitativos, tais números confirmam a estabilidade francesa e sua habilidade de renovação. Trata-se de uma história que remonta aos anos de 1930, quando a Missão Francesa teve papel nuclear na fundação dos cursos universitários na USP e na UFRJ (Miceli, 1989; Machado, 2009). Assumindo papéis que vão de modernizadores a clássicos, a tradição francesa tem sido mobilizada por diferentes gerações de acadêmicos brasileiros, tal como vimos quer nas traduções de Reclus, Sorre e Tricart realizadas pelo experiente Moreira nos primeiros anos da GEOgraphia, quer nas de Vallaux pelo doutorando William Antunes mais de uma década depois. Outro aspecto interessante revelado pelas traduções é que a França continua atraindo estudantes brasileiros de geografia, pois dos sete tradutores que "optaram" pela língua francesa, um é nativo da França (Sylvain Souchaud) e dois não estudaram por lá (Moreira e Batista), mas quatro deles (Maria Regina Sader nos anos oitenta, Haesbaert nos noventa, Ribeiro na década de 2000 e Breno Pedrosa na década seguinte) passaram por tradicionais "centros de cálculo" como o Institut d'Études Politiques, a Université de ParisSorbonne, e a École de Hautes Études en Sciences Sociales (EHESS). No geral, sete dos onze tradutores e/ou comentaristas estudaram no exterior ${ }^{3}$ e, dos quatro que verteram do francês, dois deles recorreram à Aliança Francesa (Haesbaert em Paris e Ribeiro no Rio) para aprender o idioma. Saliente-se que estamos falando de uma instituição não por coincidência fundada pelo geógrafo e colonialista Pierre Foncin em 1883 com objetivos nada ingênuos de difusão da cultura francesa através da língua (Barko, 2000), tal como exemplifica o argumento lançado na época por Vidal de la Blache sobre o papel estratégico da difusão do francês visando amenizar as tensões entre interesses metropolitanos e populações locais nas colônias (Vidal de la Blache, 1897).

21 Considerando que o idioma francês está diretamente relacionado às teses de doutorado de Ribeiro e Pedrosa, paralelamente aos seus estudos eles traduziram nomes como Vidal de la Blache, cuja influência esquecida no processo de elaboração dos conceitos de longa duração e geohistória pelo historiador Fernand Braudel foi trazida à tona (Ribeiro, 2008), e Jean Dresch, cujo impacto duplo sobre o marxismo e as abordagens anticoloniais foi significativo no que viria a ser conhecido como geografia crítica (Pedrosa, 2013). Similar abordagem pode ser estendida à língua inglesa e explicar a tradução de Sauer por Werther Holzer, cujo doutorado explorou o conceito de paisagem acerca das crônicas de viajantes estrangeiros no Brasil do século dezesseis (Holzer, 1998). Cumpre ressaltar que A educação de um geógrafo foi a única tradução do inglês no período 1999-2009, sugerindo portanto que a ideia de clássico para os geógrafos brasileiros contemporâneos guarda distância da tradição geográfica anglo-saxã representada por nomes como Semple, Bowman e Mackinder - para citar apenas alguns.

Outro indício a desvendar os mecanismos de seleção dos clássicos é que uma das poucas edições da GEOgraphia que não contém tradução (o número 8, de 2002) se deve à malograda tentativa de criar a seção Nossos Clássicos Brasileiros. Ela começou e terminou com um dos mais destacados pensadores nacionais. Dos anos trinta aos sessenta do século passado, Josué de Castro operou uma agenda geopolítica relacionando fome, raça e subdesenvolvimento chegando a alcançar reconhecimento internacional (Davies, 2019). Entretanto, o irromper do regime militar em 1964 e o impacto da geografia quantitativa da metade dos anos sessenta ao final dos setenta interromperam uma maior difusão de suas ideias. $\mathrm{O}$ fato de um brasileiro aparecer novamente após um intervalo de quinze anos (referimo-nos a Milton Santos, traduzido do inglês em 2017) 
indica que a GEOgraphia não valorizou autores nacionais que poderiam ser considerados clássicos - Delgado de Carvalho, Pedro Pinchas Geiger, Lysia Bernardes, Olga Maria Buarque de Lima Fredrich ou Lívia de Oliveira, p.ex.

A propósito da sedução exercida pelas ideias importadas, será útil comparar os números inaugurais do Boletim Geográfico - o qual, como informamos na introdução, traduziu quase quatrocentos e cinquenta textos no período 1943-1978 (Ribeiro, 2018) e da GEOgraphia. É significativo descobrir que as duas revistas escolheram verter o mesmo autor - Vidal de la Blache - em períodos intelectuais tão diferentes (1943 e 1999), o que nos leva a pensar que ambas recorreram à tradução de um autor renomado como estratégia de captação de legitimidade e prestígio. A recordar o léxico de Bourdieu, essa "transferência de capital simbólico" (Bourdieu, 2002: 5 [1990]) mostra a constância da penetração francesa na geografia brasileira. Seguindo os passos mais recentes da "francofonia" nacional nas páginas da GEOgraphia, a persistência de Haesbaert em traduzir Vidal de la Blache três vezes em três anos - 1999, 2001 e 2002 [esta com Souchaud], com destaque para o famoso artigo sobre a geografia política na obra de Ratzel - tem que ver com o fato de que, em plena ebulição das abordagens críticas marxistas, a última tradução de Vidal de la Blache no Brasil em 1982, As características próprias da geografia, tornou-se peça-chave de sua canonização entre nós desde então (cf. Ribeiro, 2020) pelo modo como interpretaram seu método descritivo e sua definição da geografia como "ciência dos lugares e não dos homens" (Vidal de la Blache, 1982: 47 [1913]). Destarte, as traduções de Haesbaert sinalizavam mudanças na recepção de Vidal de la Blache no Brasil, bem como induziriam a novas traduções e interpretações oriundas de outros tradutores, tais como a primeira parte do artigo sobre os gêneros de vida por Sader e Batista em 2005; o texto com forte teor cultural recuperando conhecimentos populares sobre paisagens, lugares e antigos caminhos da França rural e campesina; a contribuição geográfica aos fenômenos sociais; e a abordagem histórica e metodológica por ocasião de sua posse na Sorbonne. Estes três foram respectivamente traduzidos em 2006, 2007 e 2008 por Ribeiro. Por sua vez, Haesbaert volta novamente à cena ao traduzir tópicos referentes a nacionalismos $\mathrm{e}$ regionalismos extraídos de partes do livro États et nations de l'Europe autour de la France em 2009.

Totalizando oito textos em dez anos, as traduções acima encarnam uma espécie de demanda reprimida, uma necessidade de arquitetar novas narrativas sobre os clássicos em geral e sobre Vidal de la Blache em particular. Este movimento resultou na coletânea Vidal, Vidais: textos de geografia humana, regional e política (Haesbaert et al., 2012). Prefaciada por Paul Claval, ela simboliza o quão estimulante foi a seção Nossos Clássicos rumo ao ato simultâneo de traduzir e comentar as traduções. Vistas em conjunto, essa fertilidade de ideias aponta para uma convergência de pensamento entre os geotradutores no que se refere a aspectos como a originalidade de determinados textos para a constituição da geografia como ciência moderna e a necessidade de recuperá-los para as novas gerações; a ausência de material estrangeiro suficiente em português para o ensino de história da geografia; as influências exercidas pelos autores traduzidos sobre reconhecidos geógrafos brasileiros; e as traduções como chamarizes para o aprofundamento de estudos deste ou daquele clássico.

Assim, referências internacionais não são apenas citadas, mas também criticadas pelos geotradutores. Para citar alguns exemplos, em 1999 Nigel Thrift, cujo artigo Visando o âmago da região fora traduzido para o português três anos antes (Thrift, 1996 [1994]), é 
censurado no comentário de Haesbaert (em diálogo com Gomes [1996]) ao Tableau de la géographie de la France por sua leitura simplista de Vidal de la Blache.

Em contraste, o brasileiro apresenta uma outra perspectiva:

Vidal de la Blache nos deixou uma linguagem própria, um discurso que não desprezava a metáfora para enriquecer a leitura racionalista do mundo e que se desdobrava em "descrições densas" que iam muito além do empirismo e do subjetivismo de que muitas vezes ele é acusado. (Haesbaert, 1999: 140)

Na sequência, em 2002 as controversas noções de determinismo e possibilismo inventadas por Febvre (Febvre, 1991 [1922]) foram rejeitadas por Haesbaert (apoiado em Sanguin [1993]) em seu comentário à tradução de A geografia política. A propósito dos escritos do Sr. Friedrich Ratzel (Haesbaert, 2002). Por sua vez, ao traduzir O declínio do capitalismo de Jean Dresch (Dresch, 2009 [1945]), Pedrosa observa (baseado em SuretCanale [1981]) quão limitada é a interpretação de Yves Lacoste sobre o imperialismo e o subdesenvolvimento no Terceiro Mundo. Em uma passagem que sintetiza bem o espírito do trabalho desenvolvido pelos geotradutores: "Não devemos somente glorificar os clássicos, mas lê-los de acordo com nosso tempo para evitar equívocos e o escamotear de fenômenos que, por vezes, pensamos só existirem em nosso tempo" (Pedrosa, 2009: 179). No ano anterior, Ribeiro já havia divergido do mesmo Lacoste a respeito de sua leitura sobre Vidal de la Blache e seus efeitos no Brasil.

Mesmo aqueles que se esforçaram em trazer a dimensão política para a Geografia optaram por escolher a pior das estratégias: a tentativa equivocada de despolitização do pensamento vidaliano tanto o empobreceu quanto o relegou a um plano inferior (Lacoste 1988 [1976]). Sua proposta de reabilitá-lo não parece ter logrado êxito (Lacoste 1994 [1917]) - sobretudo no Brasil, onde Vidal continua sendo visto como a parte despropositada e irrelevante dos cursos de Introdução à Geografia e História do pensamento geográfico, personagem máximo de uma Geografia "simplória e enfadonha" que deve ser esquecida o mais depressa possível (Ribeiro, 2008: 125).

Saindo da órbita dos franceses, constatamos que autores alemães tiveram participação discreta na primeira década da Nossos Clássicos. Ao traduzirem fragmentos de Hettner e Humboldt em 2000 e 2004, respectivamente Moreira e Sergio Nunes Pereira - a despeito de Moreira ter escrito apenas duas páginas de comentários sobre o primeiro e da substituição de um possível comentário de Nunes Pereira por uma entrevista com Sebastien Vélut (ENS) sobre Humboldt realizada por Aldo Dantas (UFRN) em Paris (Velut, 2004) -, as escolhas dos tradutores visavam reposicionar a tradição alemã em seu devido lugar, ${ }^{4}$ algo minimizado no Brasil por causa (entre outros motivos) da francofonia. Essas traduções também sugerem quão variado é o fluxo de clássicos na periferia, pois suas origens não são alemãs, mas a coletânea espanhola que muito circulou na América Latina nos anos de 1980: El pensamiento geográfico. Estudio interpretativo y antología de textos [Geographical thinking. Interpretive study and anthology of texts] (Mendóza et al., 1982). Ainda que essa obra tenha realizado a proeza de verter quase cinquenta textos abrangendo desde Humboldt às tendências radicais, ou seja, sua amplitude temático-histórica é notável, a similaridade entre as línguas espanhola e portuguesa é que deve ser enfatizada na recepção de Hettner e Humboldt no Brasil do século vinte e um con acento castellano. Entretanto, o variado fluxo acima apontado continua tendo a Europa como norte. Assim, não é surpresa alguma descobrir, por exemplo, que Pereira passou o ano acadêmico de 2001-2002 em estágio doutoral na Espanha, mais precisamente na Universidade de Barcelona. Sua inclinação por traduzir 
a língua de Gabriel García Márquez não é, portanto, casual, mas o efeito de sua rede de formação.

Ainda sobre os alemães, embora Kant e Benjamin sejam familiares à intelectualidade brasileira devido sobretudo às traduções na área de Filosofia, até onde sabemos estamos diante de suas primeiras traduções feitas por geógrafos. Se $O$ terremoto de Lisboa (2008) é um texto curioso devido ao seu matiz geográfico, ao verter Introdução à geografia física (2007), Projeto e anúncio da geografia física (2008) e o sumário do Geografia física (2008) Leonardo Arantes - estudante de mestrado da UFF que passou uma temporada na Eberhard-Karls Universität Tübingen em 2008-2009 e cuja dissertação abordou a contribuição de Kant à geografia - atentou para as aulas de geografia lecionadas por Kant e o papel do espaço e da natureza em sua concepção de epistemologia, incluindo os discutíveis papéis por ele atribuídos à geografia, história e antropologia cujos efeitos incidiram fortemente sobre a história da geografia (ver, p.ex., Hartshorne, 1939; Schaeffer, 1953).

31 No Brasil, cumpre lembrar que a primeira tradução de Friedrich Ratzel em português, $O$ solo, a sociedade e o Estado, aparece no final da ditadura militar graças ao estudante de mestrado Mário Antônio Eufrásio (USP). Publicada em 1983 pela Revista do Departamento de Geografia da USP (Ratzel, 1983 [1898]), foi vertida do texto Le sol, la société et l'état (1900), o qual circulou em língua francesa na virada do século vinte no contexto de disputa por espaço e prestígio entre as novidades representadas pela geografia humana e pela morfologia social nas páginas do L'année sociologique, periódico fundado por Émile Durkheim em 1897 (ver Robic, 2014). Infelizmente, tanto o conteúdo do texto quanto a inciativa do tradutor em $O$ solo, a sociedade e o Estado foram esquecidos em nome da exitosa coletânea de artigos Ratzel, organizada por Moraes no interior da célebre Coleção Grandes Cientistas Sociais publicada pela editora Ática entre 1978 e 1990. Porém, embora as traduções da coletânea Ratzel tenham sido realizadas por profissionais (Fátima Murad e Denise Bottman), nenhuma delas vieram do original alemão, mas de traduções em italiano, inglês e francês (Ratzel, 1990). Além do mais, a interpretação de Moraes estava restrita, grosso modo, ao criticismo marxista e à literatura canônica (Febvre e Sodré, p. ex.) da época (Moraes, 1990). Não há menção aos importantes estudos em inglês publicados por Bassin dois anos antes, p.ex. (Bassin, 1987, 1987a).

De fato, as mudanças não tardariam a acontecer. Os anos noventa são um momento importante na história da geografia de língua portuguesa, uma espécie de transição entre os pioneiros marxistas do final dos anos setenta e decorrer dos oitenta e o impulso do início do século vinte e um. Assim, a estudante de mestrado Luciana Martins publica no maior periódico nacional, a Revista Brasileira de Geografia, o pequeno texto Friedrich Ratzel hoje: a alteridade de uma geografia (Martins, 1992). Explorando referências em espanhol, francês, inglês e alemão, ela interroga como Febvre, Semple e os marxistas brasileiros (Sodré, 1976; Moreira, 1980; Moraes, 1999 [1981], 1990; Andrade, 1987) incorreram em generalizações e estereótipos sobre Ratzel. Por sua relevância, as palavras a seguir resumem as inquietações e os programas de pesquisa da geração a emergir dentro em breve. Onde se lê Ratzel, poder-se-ia ler Vidal de la Blache, Hettner ou Kropotkin e os objetivos permaneceriam os mesmos.

Nesse sentido [a busca das origens da geografia], reler Ratzel hoje começa a tornar-se compreensível. Apesar da inquestionável importância como intelectual (...), a contribuição de sua obra para a geografia permanece ainda muito pouco explorada. $\mathrm{Na}$ verdade, até recentemente Ratzel era uma figura enigmática, esquecida. As razões desse 
silêncio relacionam-se a seus intérpretes que, após sua morte, não se preocuparam em distinguir o que era deles do que era de Ratzel. Ao selecionar as idéias do mestre, não foram capazes de evidenciar o interesse que informava a seleção realizada, fazendo com que se perpetrasse uma imagem equivocada de sua obra (Martins, 1992: 108).

Em 1993, Martins defendia seu mestrado sobre Ratzel mostrando um autor distante de ortodoxias (Martins, 1993), e em 2001 ela publica a primeira tradução dele em português realizada diretamente do alemão: Amigos, o sublime não mora no espaço (Ratzel, 2001 [1906]). Ao comentá-la, seu alvo é claro: a distorcida interpretação "francobrasileira" sobre o criador da Anthropogeographie.

A abrangente produção ratzeliana deixa transparecer a integração de fatos da modernidade e do rápido desenvolvimento da sociedade no contexto da Alemanha que se unificava. Reflexões sobre o Estado, a história, as raças humanas, o ensino de geografia e as descrições de paisagens perpassam a obra do geógrafo, que se preocupava em auferir uma identidade comum à nação em formação. No Brasil, é o Ratzel determinista que se destaca na produção historiográfica sobretudo da obra de Lucien Febvre - La terre et l'évolution humaine (1922) - que estigmatizou a pecha de determinista para Ratzel em contraposição ao possibilismo de Vidal de la Blache, termo cunhado pelo próprio Febvre (cf. Moreira, 1989: 32 e Moraes, 1990: 13) (Martins, 2001: 115).

Muito embora Ratzel tenha testemunhado profundas mudanças espaciais associadas às tecnologias de transporte e comunicações, no início do século vinte ele opta por encaminhar um argumento absolutamente inesperado em comparação com o que dele havia chegado no Brasil. Parte de uma coletânea dos assim chamados "pequenos textos" [kleinen Schriften], Amigos, o sublime não mora no espaço integra a estratégia de seleção de Martins, a qual, como geotradutora, buscou exatamente um outro prisma sobre o alemão. Assim se expressa o próprio Ratzel em língua portuguesa:

A ciência, desde que se tornou independente, não esclareceu o mistério de nossa existência (...) Uma grande parte do trabalho intelectual dos mais diversos campos da ciência foi e é gasta no esforço de demonstrar um firme progresso para além do que se denomina de nível mitológico, de estabelecer o triunfo da ciência sobre a religião e de mostrar que a inteligência humana destronou Deus (...) Mas em vão: precisamente o pensamento mais profundamente científico conduziu a Deus, a era da religião nunca terminou, nem nunca terminará, e o que se chama de idade da ciência não está acima de Deus, mas nele. (Ratzel, 2001: 119-120 [1906])

No mesmo ano de 2001, a venezuelana Acervo. Revista de Estudios Históricos y Documentales traduz do alemão para o espanhol um capítulo do negligenciado livro sobre as descrições da viagem mexicana de Ratzel em 1874-1875 encomendadas por um jornal alemão (Ratzel, 2001 [1878]. Ver Seerman e Mathewson, 2011). Ainda em 2001, Terra Brasilis, primeira revista brasileira consagrada exclusivamente à história da geografia e geografia histórica, publicou um artigo sobre a influência e adaptação da antropogeografia no processo de institucionalização da geografia em Buenos Aires (Barros, 2001). Esse Zeitgeitst latino-americano ao redor de Ratzel não nos parecem nada casuais. Muito pelo contrário, eles apenas reforçam a ideia de que tradução e ciência são partes centrais da dinâmica explicativa da história da geografia em países periféricos. 


\section{Crescimento, novos agentes, consolidação (2010-2019): mais que traduzir} diferentes fontes, 19 tradutores, 17 comentários, 13 autores traduzidos de 5 nacionalidades (alemães, franceses, russos, britânico e brasileiro) e de 4 idiomas (alemão, francês, russo e inglês). As principais fontes, autores traduzidos e tradutores são capítulos [7] do livro Geografia, sua história, essência e métodos, de Hettner [7], e Leonardo Arantes [14]. Em geral, autores alemães aparecem 16 vezes (7 Hettner, 5 Ratzel, 2 Humboldt, 2 Ritter), franceses 7 vezes (2 Reclus, 2 Vallaux, 1 George, 1 Lefebvre, 1 Ronai), russos 3 vezes e brasileiros e britânicos uma única vez cada (Mackinder e Santos).

Enquanto a quantidade de idiomas é a mesma do decênio anterior (quatro), o número de fontes decresceu por causa do mergulho de Arantes em vários capítulos de um único livro de Hettner acima citado, além de ter dividido a tradução do Espaço da vida: um estudo biogeográfico (2019 [1900]), de Ratzel, em três partes. As nacionalidades, por sua vez, aumentaram apenas um ponto (4 para 5), mas o principal incremento se deu no número de traduções e de tradutores: enquanto estes eram em 11 durante 1999-2009, passaram para 14 novos nomes em 2010-2019. Oito deles vieram de fora da UFF, enquanto na primeira década apenas três eram de outras instituições. A seção Nossos Clássicos tornou-se atrativa também por ter permitido as primeiras traduções e publicações por parte de pós-graduandos e recém-doutores. Além disso, equilibrando-se entre a necessidade de material pedagógico e a fórmula publish-or-perish, muitos professores também atuaram: enquanto quatro docentes e sete pós-graduandos ou recém-doutores participaram traduzindo ou comentando de 1999 a 2009, onze docentes e oito estudantes de graduação, pós-graduandos e recém-doutores atuaram no período 2010-2019.

Outras diferenças da segunda década para a anterior são as seguintes: primeiro, o predomínio alemão é algo digno de nota, tendo Hettner e Ratzel à frente. Segundo, a presença de jovens autores, muitos deles nascidos no século vinte - incluindo Maurice Ronai, o único vivo entre os traduzidos -, pode ser vista como um desejo de trazer os clássicos para mais perto do tempo presente, p.ex. Terceiro, a inclinação política dos traduzidos aponta para um perfil de esquerda, conforme os legados deixados por Reclus, Kropotkin, Lefebvre, George e Santos. Por fim, os comentários são mais longos, detalhados e combativos. Em conjunto, nota-se uma mudança no sentido de como os clássicos vêm sendo concebidos, significando também que os geotradutores não estão satisfeitos apenas em apresentar as traduções. Eles as interpretam, questionando sua recepção prévia e canônica responsável por orientar a história da geografia no Brasil. Analisaremos a seguir alguns exemplos desses questionamentos.

41 Ao traduzir o segundo artigo de Ratzel em português do original em alemão, Marcos Bernardino de Carvalho (2010) argumentou que embora as simplificações sobre Ratzel permanecessem, começara também um forte movimento para redescobri-lo, incluindo brasileiros pioneiros como Martins e estrangeiros celebrados como Raffestin. Neste contexto, ao verter o notável Sobre a interpretação da natureza (2010 [1904]) - cujo conteúdo problematiza a representação geográfica e as funções da arte e da linguagem -, observamos que as intenções de Carvalho foram semelhantes às de Martins, ou seja, expandir a recepção de Ratzel para além de seu legado geopolítico e determinista. Eis a

Terra Brasilis, 15 | 2021 
razão pela qual ele afirma que "Cremos que o texto cuja tradução apresentamos a seguir poderá contribuir ainda mais para essas reconsiderações que em torno do pensador alemão se promovem" (Martins, 2010: 147). Além disso, ao empregar o termo "caricatura" referindo-se à dicotomia febvriana determinismo-possibilismo (Carvalho, 2010: 143), ele estava em sintonia com Mariana Lamego, cuja tese doutoral no mesmo ano da tradução de Carvalho avaliava que a abordagem quantitativa havia se tornado uma caricatura - a palavra estampa o título da tese - por causa das leituras feitas no Brasil por alguns integrantes das abordagens radicais nos anos setenta e oitenta (Lamego, 2010). Por último, tal como Carvalho já o fizera em dois artigos anteriores sobre o próprio Ratzel (Carvalho, 1997, 1997a), nenhum dos pioneiros livros marxistas sobre história da geografia (Sodré, 1976; Moreira, 1980; Moraes, 1999 [1981]; Andrade, 1987) foi citado em seu comentário sobre a referida tradução.

Na mesma direção, no comentário que antecede uma sequência de traduções inéditas de Hettner em português - nas quais podemos acompanhar seus esforços teóricos em definir a geografia como uma ciência humana e natural visando explicar as diferenças espaciais sobre a superfície terrestre (Hettner, 2011, 2011a, 2012, 2013), Sahr (alemão radicado no Sul do Brasil e professor da UFPR) e Arantes (2011) traçam um erudito painel mostrando diversas facetas de Hettner, tais como a importância dos trabalhos de campo (duas viagens à América do Sul em 1882-1884 e em 1888-1890, por exemplo), a atuação em projetos editoriais (a fundação da revista Geographische Zeitschrift em 1895) e a concepção teórica de que o objeto da geografia era a corologia. Ao fazê-lo, Sahr e Arantes também não mencionaram as referências marxistas acima citadas. Alguns anos mais tarde, em seu comentário sobre o texto de Ritter 0 elemento histórico na ciência geográfica (2018 [1835]), Arantes reclama não entender como uma ideia tão importante como a "aniquilação do espaço pelo tempo" - concebida por Marx e redescoberta por Harvey um século depois - pôde ser negligenciada no desenvolvimento da geografia (Arantes, 2018: 139-140). E, ao examinar a recepção do artigo de Ritter, Arantes também deixa seu registro crítico sobre os livros marxistas brasileiros supracitados:

No contexto ibero-americano a situação é ainda mais complexa; o tratado de Ritter passou igualmente quase despercebido em trabalhos cruciais de epistemologia e história do pensamento geográfico, tais como, por exemplo, em Santos (1979), Moreira (1981), Capel (1982), Andrade (1987), Moraes (1989), Gomes (1996) e Valcárcel (2001), muito embora em alguns deles questões afins inclusive presentes em outros textos do geógrafo alemão, tenham sido suscitadas e, de algum modo, contempladas. (Arantes, 2018: 139)

Visto que a produção científica não pode ser dissociada de seu contexto histórico, ao ocupar gradualmente os principais departamentos universitários nas décadas de oitenta e noventa os geógrafos críticos promoveram uma revolução silenciosa em um país onde a geografia sempre foi negócio de Estado. Graças a eles, foi possível ler o território brasileiro a partir de suas contradições, e não temos dúvida de que se a maioria dos geógrafos brasileiros de esquerda permanece imbuída do espírito crítico o mérito pertence às abordagens ditas radicais. Entretanto, sob o signo da Guerra Fria, da Descolonização e das lutas contra a ditadura militar pelo restabelecimento da democracia, grosso modo os pioneiros livros sobre história da geografia redigidos à luz do marxismo representaram clássicos como Ratzel, Vidal de la Blache e Mackinder como uma espécie de tradição negativa devido aos seus vínculos com o imperialismo e o capitalismo. Por outro lado, beneficiada por arquivos digitais, trocas internacionais aceleradas e diversificadas e viagens de pesquisas no exterior, no início do século vinte 
e um emergia uma nova geração cujo olhar para os clássicos será um pouco diferente do de outrora. Ao traduzir $O$ ensino de geografia sob a ótica imperial e os usos que podem e devem ser feitos da instrução visual, de Mackinder (2014 [1911]), Ribeiro enfatizava quão complexos são os clássicos mesmo quando discordamos de suas tendências políticas. No caso em tela, a manipulação da paisagem a fim de disseminar uma ideológica unidade cultural entre a metrópole britânica e suas colônias nos livros didáticos de geografia.

Cabe perguntar: quais motivos políticos estão por trás desta movimentação [a busca pela trajetória da geografia]? Sim, pois não se trata meramente de recuperar uma herança em nome de uma tradição a ser permanentemente atualizada, mas de compreender tanto o engajamento dos clássicos da geografia com o colonialismo para além dos estereótipos quanto identificar a contribuição deles no exame da constituição do mundo moderno. Em termos claros, é mister separar o joio do trigo, pois, se rejeitarmos a priori a obra de nossos antecessores por causa de suas orientações políticas conservadoras, corremos o risco de sermos (ou, de certa forma, já somos?) uma corporação em constante crise de identidade. (Ribeiro, 2014: 154)

Uma das evidências mais reveladoras tanto do crescente interesse brasileiro em problematizar os clássicos e a história da geografia por meio de traduções quanto do impacto da própria seção Nossos Clássicos está no trabalho do doutorando William Antunes. Ao verter As aspirações regionalistas e a geografia (2015 [1928]) ao lado de Haesbaert e Juliana Nunes Rodrigues (ambos professores da UFF e outrora estudantes na França, ressalte-se) e uma resenha sobre Febvre, Vidal de la Blache e Arbos (2017 [1923]), interpretamos sua escolha por Camille Vallaux como um efeito das reiteradas traduções de Vidal de la Blache, despertando assim a vontade de assimilar a Escola Francesa de Geografia sob novos ângulos, sob a ótica de um intelectual de relevo porém à part entière do establishment vidaliano. Na mesma direção, podemos notar também que o perfil aqui esboçado dos geotradutores se repete, possui certa consistência. Afinal, Antunes desde 2013, Pedrosa em 2013 e Ribeiro em 2007-2008 integraram o mesmo grupo de pesquisa em Paris liderado por Marie-Claire Robic, o EHGO, decidiram traduzir para o português as fontes francesas de seus trabalhos doutorais durante a confecção das teses e escolheram a mesma revista para divulgá-los.

A nosso ver, Nossos Clássicos têm atuado como um imã no sentido de atrair e "formar" diferentes gerações rumo à tradução. Nesse segundo decênio, podemos observar este movimento na tradução de dois pequenos prefácios de Ratzel para Politische Geographie em 1897 e 1903 efetuada pelo licenciado Marquessuel Dantas de Souza e pelo mestre Gabriel Reichenheim, bem como na tradução de Mackinder co-assinada pelo bolsista de iniciação científica Leroy Honorio Azevedo. Este gênero de trabalho, grife-se, não tem nada de aleatório. Ele é a consagração de uma rede à la Latour (Latour 1987) tecida por escalas, negociações e instituições as mais diversas e cujo escrutínio nos permite iluminar uma parcela do regime de tradução efetuado na periferia da ciência. No caso do Brasil, o trabalho de traduzir tem sido essencial para que um público mais amplo possa acessar debates estrangeiros e incrementar sua formação e sua prática como um todo. Todavia, há algo além disso. Traduzir não é o ato passivo de transmitir ideias importadas, mas um gênero de "método" apto a desestabilizá-las. Mais que simples "meio" empregado a fim de que as ideias possam viajar de uma língua e de um lugar para outro, na GEOgraphia traduzir tornou-se a estratégia privilegiada para que uma nova geração expressasse suas insatisfações e desenvolvesse leituras anti-canônicas tanto em relação ao que têm sido produzido no Brasil quanto no exterior. Exemplo disto é a crítica tanto ao conceito de "círculo de afinidades" idealizado pelo francês 
Vincent Berdoulay em seu estudo sobre a formação da Escola Francesa de Geografia (Berdoulay, 1995 [1981]) quanto à sua apropriação automática por alguns geógrafos brasileiros.

Na verdade, é em sua obra [a de Vallaux] que se encontra o pensamento crítico da Geografia clássica. Assim, nota-se que a história da Geografia francesa é escrita por doutorandos e pesquisadores da Sorbonne e, por isso, aqueles que dela não fazem parte, como Camille Vallaux, Albert Métin e Louis Gallouédec, são vistos como marginais. Lá onde os historiadores utilizam a palavra "marginal" é na verdade uma palavra tampão para proteger personagens clássicos. Estar "distante" ou "ser marginal" foi uma forma que certos historiadores da Geografia encontraram para proteger um circuito de geógrafos e esse estilo historiográfico está se reproduzindo na Geografia brasileira, através da expressão tão famosa "cercle vidalien". É o que chamamos de palavra tampão. As palavras tampão são sempre utilizadas para isolar, até mesmo esterilizar a obra de um determinado autor, enquanto continuam preservando a imagem e o regime histórico de geógrafos canônicos. (Morais, 2015: 201)

De volta após longo exílio na Europa, África e Américas do Norte e Sul imposto pela ditadura militar nos anos sessenta e setenta - quando teve oportunidade de discutir o subdesenvolvimento brasileiro e a teoria do subimperialismo com outros exilados como Ruy Mauro Marini, tal como aprendemos com o comentário de Thiago Machado para a tradução do artigo de Santos Sub-imperialism, as viewed by a geographer do inglês para o português (Machado, 2017; Santos, 2017 [1975]) -, Santos logo percebeu a necessidade de "erguer uma geografia brasileira descolonizada" (Santos, 1982: 216) a partir da realidade nacional e da edificação de uma teoria universal made in Brazil capaz de romper com a reprodução indiscriminada de conceitos estrangeiros. Este é um tópico complexo e não temos espaço para desenvolvê-lo aqui. Todavia, ele é indissociável do principal argumento do presente artigo, isto é, não podemos mais negligenciar o papel historicamente jogado pelas traduções na moldagem do imaginário nacional sobre os clássicos e a história da geografia em geral. Por ora, cabe pensar alto e dizer que do ponto de vista periférico estamos convencidos de que o projeto de descanonização da geografia proposto por Keighren et al. (2012) só fará completo sentido se vier acompanhado da descolonização da disciplina (Ribeiro, 2015a).

Embora não diretamente inspiradas pela decolonialidade, cremos que em geral as traduções e os comentários publicadas em Nossos Clássicos partam de geógrafos cujas intenções político-intelectuais consistem em interpretar a história da geografia a partir de direções alternativas às já consagradas. Ao fazê-lo, um procedimento crucial é o de questionar o status de "programáticos" ou "menores" atribuídos - indiretamente - a este ou àquele texto como forma de classificar e ler a obra dos clássicos. É preciso, sim, investigar quais textos têm sido privilegiados e negligenciados, por quem e por quais razões. Afinal, a seleção das fontes (traduzidas ou não) é responsabilidade do pesquisador e, como tal, desnuda parte de suas intenções. Mesmo diante de um autor tão clássico quanto Humboldt, a diversidade de sua obra e a vontade de explorá-la por outros ângulos levou Arantes a ir além da geografia dos plantas, por exemplo (Humboldt e Bonpland, 1805), contribuindo desde os Trópicos para as releituras do prussiano em escala internacional (Wulff, 2015; Péaud, 2019). Assim, ao criticar os efeitos da escravidão e do sistema colonial, muito embora as posições de Humboldt a respeito sejam objeto controverso (Pratt, 1992; Sachs, 2003) a reflexão a seguir é muito importante para ser esquecida. 
O fato é que a própria ideia de colônia é uma ideia imoral, é a ideia de uma terra que se torna tributária de uma outra, de uma terra na qual se deve chegar apenas a um certo grau de prosperidade, na qual a indústria, as luzes devem se expandir até um certo ponto (...) [Europeus] Disputam qual nação trata os negros com mais humanidade, isto é, fazem piada com a palavra humanidade e perguntam se é mais agradável ser cortado ou esfolado, perguntam se os espanhóis fizeram mais crueldades no Peru do que na Venezuela, se os espanhóis fizeram mais na América do que os ingleses e franceses nas Índias orientais!! (Humboldt, 2016: 173-174 [1803])

48 Essa politização dos clássicos ou, em certa medida, sua dessacralização, é fundamental, e as traduções de Reclus e Kropotkin também sinalizam vários aspectos nessa direção. Nas páginas da GEOgraphia os anarquistas surgem como uma vontade de abordar a história da geografia em termos menos teóricos e mais políticos e a partir de temáticas que guardem alguma correspondência com os dias atuais. Além disso, a circulação deles entre nós é de extremo valor por rechaçar qualquer tipo de determinismo histórico segundo o qual a adesão ao colonialismo no século dezenove era algo típico da época e, portanto, todos os geógrafos de então eram imperialistas e, de uma forma ou de outra, darwinistas sociais (ver Ferretti, 2018). Essa circulação ocorre naquele que é provavelmente o período mais receptivo da geografia brasileira às ideias anarquistas, feito possível graças sobretudo aos esforços do tradutor e militante Plínio Augusto Coêlho e do grupo de jovens ao redor dele e do site Biblioteca Terra Livre. ${ }^{5}$

Ilustremos o alcance do tom político de Reclus. Ciente do perigoso casamento entre nacionalismo e fronteiras e seus desdobramentos em termos de exclusão e desigualdade, em 0 patriotismo é incompatível com o amor pela humanidade? (Reclus, 2018 [1904]) ele condena o núcleo de uma estrutura ideológica na qual os geógrafos contribuíram sobremaneira para instituir: o Estado Nacional Territorial.

(...) deve-se reconhecer que a pátria e seu derivado, o patriotismo, são uma deplorável sobrevivência, o produto de um egoísmo agressivo que somente pode conduzir à destruição, à ruína das obras humanas e ao extermínio dos homens. Mas o povo é ingênuo, e sob esta palavra "pátria" fizeram-no compreender mil coisas, doces ou belas que de modo algum comportam a divisão da terra em parcelas inimigas (...) E é para defender ou estender esses limites absurdos que guerras sucederam guerras: era preciso que cada limite fosse estabelecido sobre cadáveres, como outrora ocorreu com cada porta da cidade. (Reclus, 2018: 113 [1904])

Do lado de Kropotkin, A descentralização da indústria (Kropotkin, 2018 [1898]) é um texto em que o russo reverte a apologia de Adam Smith sobre a moderna divisão do trabalho em prol de sua integração, a qual inclui a recusa à automatização do labor humano. Já em As guerras e o capitalismo (Kropotkin, 2014 [1914]) - traduzido pelo geógrafo anarquista Amir El-Hakim de Paula visando "inserir mais ainda as discussões do autor nos vários cursos de formação de geógrafos" (El-Hakim de Paula, 2014: 172. Ver, também, El-Hakim de Paula, 2019) - Kropotkin denuncia como conflitos têm sido patrocinadas por bancos e Estados visando benefícios financeiros e territoriais e como grupos midiáticos são coniventes com eles. Associando economia, competição industrial e imperialismo, uma breve comparação com Ratzel, Vidal e Mackinder revelará uma diferença abissal de pensamento no tratamento das relações internacionais:

A China há vários anos vem sendo dividida por um cartel representante dos grandes bancos da Inglaterra, França, Alemanha e dos Estados Unidos. E, desde a Revolução na China, Rússia e Japão exigem participação nesse cartel. Eles querem lucrar com a intenção de estender não só suas esferas de exploração, mas também seus 
territórios. A divisão da China, preparada pelos banqueiros, está nesse momento na ordem do dia. (Kropotkin, 2014: 179 [1914])

51 e canônico, sobretudo quando acentuamos o papel do lugar na maneira como os definimos e representamos. Colocar em relevo a própria geografia da história da geografia faz com que ela se torne muito mais complexa que qualquer narrativa cronológica e teleológica possa imaginar. Explique-se: no Brasil, o total desconhecimento a respeito de Vallaux e, mesmo, de Kropotkin faz com que eles não possam ser considerados nem clássicos, nem canônicos. Humboldt, Ritter e Reclus são clássicos, mas estão longe de serem canônicos. Ratzel, Vidal de la Blache e Sauer são clássicos, mas foram canonizados. Enfim, o que os classifica deste ou daquele modo é o tratamento que eles receberam no âmago de suas respectivas recepções. Neste sentido é que Nossos Clássicos marca data, pois a agência e a agenda dos que nela intervém, ao não se limitarem apenas a traduzir, revelam uma postura crítico-alternativa em relação ao que havia sido consagrado - aos cânones, portanto - pelos historiadores da geografia no Brasil. Clássico e canônico, destarte, não são noções abstratas e apriorísticas; para que elas façam pleno sentido, é preciso que sejam confrontadas com os lugares científicoinstitucionais e os contextos histórico-intelectuais que as acolheram. De toda forma, e a despeito de sua atual recepção crítica, a hegemonia da presença europeia é um forte indício da centralidade do "Velho Mundo" em nosso imaginário geográfico. No mesmo tom, o malogro da seção Nossos Clássicos Brasileiros sinaliza o desinteresse para com a riqueza geográfica made in Brazil.

\section{Conclusão}

O presente artigo abordou a história recente da geografia brasileira sob a perspectiva das traduções e dos tradutores. Tomando como fonte a seção Nossos Clássicos publicada pela revista GEOgraphia entre 1999 e 2019, nosso objetivo foi mostrar em termos quantitativos e qualitativos quem são esses clássicos, quem os trouxe para a língua portuguesa, a natureza de seus comentários e as razões que os levaram a traduzir. Para explicar esse material, articulamos contribuições oriundas dos translation studies e do pensamento decolonial visando ressaltar a tradução como objeto geográfico e geopolítico e o tradutor como agente fundamental na circulação científica (Venuti, 1995, 1998; Mignolo, 2000, 2012; Buzelin, 2005, 2010; Rupke, 2000; Bachmann-Medick, 2009; Casanova, 2015). Neste quadro, a condição de ser e estar na periferia da divisão acadêmica do trabalho é uma estrutura histórica e política da maior relevância no entendimento da considerável sucessão de traduções mobilizadas pela geografia brasileira desde o Boletim Geográfico (1943-1978) à GEOgraphia (1999-2019).

Em termos quantitativos, GEOgraphia publicou 47 edições, 25 tradutores (sendo 3 estrangeiros), 48 traduções provenientes de 5 idiomas (alemão, francês, inglês, espanhol e russo) e 33 fontes diferentes, além de 36 comentários e 20 autores traduzidos, sendo 9 franceses, 6 alemães, 2 russos, 1 norte-americano, 1 britânico e 1 brasileiro. Os três principais clássicos traduzidos foram Vidal de la Blache, Hettner e Ratzel, com respectivamente 8, 8 e 6 aparições. Os principais tradutores foram Arantes (17), Haesbaert (10), Moreira (4) e Ribeiro (4), enquanto as fontes foram os capítulos do livro de Hettner Geografia, sua história, essência e métodos (7 vezes), a revista Annales de Géographie (5 vezes) e o texto de Ratzel Espaço da vida: um estudo biogeográfico (3 vezes). 
Livros aparecem em 20 ocasiões, ao passo que revistas em 10 delas - considerando apenas fontes não-repetidas. Sublinhando o ato de traduzir como processo geopolíticocultural e movimento sócio-geográfico, dos 22 estudantes de graduação, pós-graduação e professores brasileiros envolvidos, 13 deles estudaram no exterior, sendo 10 na Europa (França, Espanha, Alemanha, Inglaterra e Portugal), 2 nos Estados Unidos e 1 em Cuba, ao passo que os outros 9 não saíram do Brasil. Conclui-se, portanto, que embora a experiência internacional não seja condição sine qua non para traduzir, ela é um impulso crucial pois, na Nossos Clássicos, todos os brasileiros que estudaram fora acabaram por traduzir. Em termos qualitativos, grife-se, de um lado, o poder simbólico-intelectual exercido pela Europa sobre tradutores brasileiros e, de outro, o desinteresse pela tradição geográfica anglo-saxã nas primeiras décadas do século vinte e um. Embora a francofonia permaneça forte (20 aparições), a incidência dos alemães (21 vezes) reposiciona em devido lugar seu pioneirismo na institucionalização e na teorização da moderna geografia universitária no decorrer do século dezenove e na primeira metade do século XX. Por sua vez, a frequência conjunta de Reclus (4 vezes) e de Kropotkin (2 vezes) é um sinal de que a geografia brasileira deseja reverter a negligência por eles sofrida em língua portuguesa e explorar seu potencial político-interpretativo em tempos de crise.

São vários os fatores que impelem geógrafos ao trabalho de tradução: evitar generalizações e caricaturas acerca dos clássicos, ampliar a oferta de material didático em língua portuguesa para os cursos de história da geografia, evidenciar as pesquisas dos próprios tradutores e suas experiências internacionais, abrir espaços de publicação. Entretanto, uma vez que as traduções em tela são acompanhadas de comentários críticos, elas acabam assumindo o papel de "álibi" (nossas aspas) para repensar leituras canônicas nacionais e internacionais em torno dos clássicos, tal como apontam a recorrência de livros como Introdução à geografia: geografia e ideologia (Sodré, 1976), o que é Geografia? (Moreira, 1980), Geografia: pequena história crítica (Moraes, 1999 [1981]), Geografia, ciência da sociedade: uma introdução à análise do pensamento geográfico (de Andrade, 1987), A geografia - isso serve, em primeiro lugar, para fazer a guerra (Lacoste, 1988 [1976]) e A terra e a evolução humana: introdução geográfica à história (Febvre, 1991 [1922]). Na medida em que tais obras ou inventaram ou reproduziram a dicotomia possibilismo-determinismo em particular e simplificaram os clássicos em geral, ${ }^{6} \mathrm{o}$ fato de que Vidal de la Blache e Ratzel apareçam entre os autores mais traduzidos é emblemático da insatisfação de toda uma geração com aquelas narrativas canônicas. Mais atentos ao multilingualismo e ao cenário internacional que a geração precedente, a preferência agora recai sobre os textos originais e traduções diretas do original ao invés de interpretações de segunda-mão em português e em outros idiomas. Destarte, graças aos seus próprios comentários, geotradutores saem das sombras (para não dizer da invisibilidade, cf. Venuti, 1995) e, interferindo ativamente na recepção dos autores por eles selecionados, abrem caminhos para transformar os rumos da história da geografia praticada no Brasil. Agindo assim, eles acabam por, de certa forma, interagir com movimentos de língua inglesa (Keighren et al., 2012; Ferretti, 2019).

Enfim, uma vez que o foco dos geotradutores recaiu sobre as leituras canônicas ao redor da história da geografia, em contrapartida restou a sensação de que o ato de traduzir a partir de um país e uma língua periféricas é algo muito mais implícito que explícito, mais inconsciente que consciente. Não sendo neutras nem transparentes, as relações de poder envolvendo centro e periferia e as assimetrias entre diferentes tradições geográficas poderiam ter sido elaboradas pelos geotradutores de alguma 
maneira. Não podemos relativizar o fato de que línguas e culturas europeias têm exercido uma atração um tanto quanto fetichista sobre a imaginação do Novo Mundo. Concebido por Quijano como a "colonização do imaginário" (Quijano, 2000), esse mecanismo tem embaraçado o despertar de uma consciência mais crítica por parte dos geotradutores acerca de seu próprio métier. Sabendo que a maior parte dos geotradutores passou por universidades europeias, tendo sido portanto confrontados com toda sorte de adversidades linguístico-culturais, a ausência de problematização sobre a geopolítica do conhecimento no ato de traduzir deve ser repensada. Tal ausência, porém, está longe de ser especificidade dos geotradutores brasileiros, pois sabemos que a academia como um todo tem ignorado as traduções, e tampouco significa que o trabalho de tradução ocorreu de modo acrítico - as páginas anteriores mostram exatamente o contrário. Ao evidenciá-la, estamos apenas tentando chamar atenção para a necessidade de encarar a tradução para além dos aspectos linguísticoestilísticos. ${ }^{7}$ Não terá Schulte toda razão ao observar que tradutores têm falhado quando se trata de educar seus leitores? (Schulte, 2012. Ver, também, Venuti, 2004).

A situação acima descrita guarda direta correspondência com o matiz eurocêntrico da seleção agenciada pelos geotradutores. Dos vinte autores traduzidos, apenas Sauer, Sochava e Kropotkin fogem a essa geografia. Efetivamente, o radar dos geotradutores brasileiros não foi capaz de ultrapassar os limites da Europa. Com sua língua dominada, o castelhano, nossos vizinhos latino-americanos foram solenemente ignorados. Pior: desconfiamos que nem saibamos quem eles são. De toda maneira, descolonizar e deslocar o currículo e a noção de clássicos para fora da Europa são tarefas que estão na agenda do pensamento progressista. Exemplo recente foi dado pelos brasileiros André Nunes de Sousa e Caroline Bulhões Nunes Vaz ao recuperarem o pioneirismo do "engenheiro-geógrafo" Theodoro Sampaio (1855-1937) em um período (ainda pouco estudado) anterior à institucionalização universitária da década de 1930 (Sousa e Vaz, 2019). Baiano e negro, ler a história da geografia brasileira a partir de Sampaio já é, por si só, uma releitura, na medida em que reposiciona tanto a centralidade do eixo Rio-São Paulo quanto a da Missão Francesa. Em espaços e contextos hegemonizados por homens brancos heterossexuais como o foram as sociedades geográficas e as universidades no século dezenove e na maior parte do vinte, apenas um negro foi vertido como clássico na GEOgraphia: Milton Santos.

Outra questão de monta diz respeito ao gênero feminino. Dado sintomático a reforçar a discriminação de gênero na ciência em geral e na geografia brasileira em particular (ver, a respeito, Silva, 2009), nenhuma mulher foi traduzida na seção Nossos Clássicos. Estamos falando de uma dominação masculina cujo modus operandi, na medida em que consiste em excluir mulheres da ciência, dificulta o trabalho de "simplesmente" encontrá-las (tal como fazemos com nomes masculinos) nos anais da geografia - e, mais ainda, fora das áreas centrais. De todo modo, nomes como a norte-americana Ellen Churchill Semple (1863-1932) (ela própria tradutora de Ratzel para o inglês [ver Keighren, 2010]), a francesa Jacqueline Beaujeu-Garnier (1917-1995) e a francoportuguesa Suzanne Daveau (1925-) nos vêm à cabeça. Na sequência, chama atenção a baixa participação de mulheres tradutoras - apenas 5 de 25 -, ainda mais quando recordamos suas atuações significativas em outros momentos da história da geografia nacional como as traduções do Boletim Geográfico (1943-1978) e de livros marxistas no desenvolvimento das abordagens radicais entre o final da década de 1970 e o decorrer da de 1980 (Ribeiro, 2018; Siebert, 2019). 
Para finalizar, gostaria de compartilhar a impressão segundo a qual os geógrafos brasileiros de modo geral parecem desconfiar do alcance político, crítico e progressista daqueles que se dedicam à história e à teoria da geografia. Se houver alguma razão de ser nessa impressão, que ela seja revertida o quanto antes. Inspirado por Paulo Freire (Freire, 2013 [1968]) - cuja atualidade é inquestionável tanto no que se refere a entender o negacionismo quanto como advertência ao autoritarismo derivado não só da direita, mas também da esquerda -, creio que disciplinas introdutórias como História da Geografia devem ser úteis não para apresentar as ricas tradições geográficas de cima para baixo em um desfile elitista de idiomas e nomes estrangeiros. Elas possuem a capacidade de empoderar os estudantes - majoritariamente vindos de camadas populares, periferias e comunidades - sublinhando o fato de que suas experiências familiares, de vida, de trânsito e de sobrevivência na Região Metropolitana do Rio de Janeiro fazem deles, em muitos aspectos, geógrafos antes mesmo de ingressarem no curso universitário de geografia. Há muita práxis nessa forma de pensar. Há muito de movimento social no cotidiano de um curso de História da Geografia. Textos, seminários e, particularmente, traduções consagradas a esse ramo não são apenas discursos intelectuais pertencentes a um passado distante e idealizado, mas práticas de formação política e cultural que não perdem de vista nem o presente, nem a possibilidade de reescrever o passado. Tudo isso faz parte da resistência em um país estruturalmente escravocrata, violento e autoritário como o Brasil.

Em suma, um regard critique em relação à língua e ao ato de traduzir é o próximo passo a ser tomado pelos geotradutores brasileiros. Não obstante as ponderações anteriores, não temos dúvidas de que a seção Nossos Clássicos da revista GEOgraphia tornou-se fonte privilegiada de leitura e discussão críticas acerca da história da geografia e da circulação do conhecimento em um país periférico como o Brasil.

\section{BIBLIOGRAFIA}

Aalbers, M. B. (2004). Creative destruction through the Anglo-American hegemony: a non-AngloAmerican view on publications, referees and language. Area 36.3, 319-322.

Andrade, M.C. de (1987). Geografia, ciência da sociedade: uma introdução à análise do pensamento geográfico. São Paulo: Atlas. 143pp.

Anzaldúa, G. (1987). Borderlands/La frontera. The new mestiza. San Francisco: aunt lute books. 300 pp.

Anzaldúa, G. (1981). Speaking in tongues: a letter to third world women writers. In: Moraga, C., Anzaldúa, G. (Edited by). This bridge called my back: writings by radical women of color.

Massachussets: Persephone Press, 165-173.

Apter, E. (2006). The translation zone. A new comparative literature. Princeton and Oxford: Princeton University Press. 298pp.

Bachmann-Medick, D. (2016 [2015]). Cultural turns. New orientations in the study of culture. Translated by Adam Blauhut. Berlin/Boston: Walter de Gruyter GmbH. 298pp. 
Bachmann-Medick, D. (2009). The translational turn. Translation Studies, vol. 2, n.1, 2-16. Barko, I. (2000). L'Alliance française: les années Foncin (1883-1914). Contexte, naissance, mutations. Documents pour l'histoire du français langue étrangère ou seconde, 25, 90-115.

Barros, C. (2001). La antropogeografía en Buenos Aires. Terra Brasilis, 3, 1-15.

Bassin, M. (1987a). Friedrich Ratzel (1844-1904). Geographers: Biobibliographical Studies, vol. 11, 123-132.

Bassin, M. (1987). Imperialism and the nation state in Friedrich Ratzel's political geography. Progress in human geography, 11, 473-495.

Berdoulay, V. (1995 [1981]). La formation de l'école française de géographie. Paris : Bibliothèque Nationale/Éditions du C.T.H.S. 253p.

Bourdieu, P. (2002 [1990]). Les conditions sociales de la circulation internationale des idées. Actes de la recherche en Sciences Sociales, vol. 145, décembre, 3-8.

Braudel, F. (1997). Les ambitions de l'histoire. Édition établie et présentée par Roselyne de Ayala et Paule Braudel. Paris: Éditions de Fallois. 663p.

Broc, N. (1977). La géographie française face à science allemande (1870-1914). Annales de Géographie, 473, jan/fév., 71-94.

Buzelin, H. (2010). Agents of translation. In: Gambier, Y., Doorslaer, L. van (edited by). Handbook of Translation Studies. Volume 2. Amsterdam/ Philadelphia: John Benjamins Publishing Company, pp. 6-12.

Buzelin, H. (2005). Unexpected Allies. The Translator, 11:2, 193-218.

Carvalho, M. (1997a). Ratzel: releituras contemporâneas. Uma reabilitação? Biblio 3W. Revista de Geografia y Ciencias Sociales, n 25, 1-20.

Carvalho, M. (1997). Diálogos entre as Ciências Sociais: um legado intelectual de Friedrich Ratzel (1844 - 1904). Biblio 3W. Revista de Geografia y Ciencias Sociales, n. 34, 1-32.

Casanova, P. (2015). La langue mondiale. Traduction et domination. Paris: Seuil. 129p.

Cronin, M. (2003). Translation and globalization. London and New York: Routledge 197pp.

Dantas, E., Augustin, C. Cavalcanti, L. (2013). Documento de área: Geografia. Brasília: Ministério da Educação, Capes. 43p.

Davies, A. (2019). Josué de Castro's Geografia Combatente and the political ecology of hunger. London: $\mathrm{PhD}$ in Geography at King's College London. 306p.

De Andrade, O. (2017 [1928]). Manifesto antropófago. In: ANDRADE, Oswald de. Manifesto antropófago e outros textos. Penguin \& Companhia das Letras, 49-60.

De Campos, H. (2006 [1963]). Da tradução como criação e como crítica. In: de Campos, H. Metalinguagem \& outras metas: ensaios de teoria e crítica literária. São Paulo: Perspectiva, 31-48.

Desbiens, C. (2002). Speaking in tongues, making geographies, Society and Space 20 1-3.

Desbiens, C., Ruddick, S. (2006). Speaking of geography: language, power, and the spaces of Anglo-Saxon 'hegemony'. Society and Space 24, 1-8.

Febvre, L. (1991 [1922]). A terra e a evolução humana. Introdução geográfica à história. $2^{\mathrm{a}}$ ed. Lisboa: Cosmos, 339p. Tradução de Jorge Borges de Macedo. 
Ferretti, F. (2019). Rediscovering other geographical traditions. Geography Compass, Volume 13, Issue3, March, 1-15.

Ferretti, F. (2017). Evolution and revolution: Anarchist geographies, modernity and poststructuralism. Environment and planning D: Society and Space, volume 35, issue 5, 893-912.

Foucault, M. (1971 [1970]). L'ordre du discours. Paris: Gallimard. 82p.

Freire, P. (2013 [1968]). Pedagogia do oprimido. São Paulo: Paz e Terra. 202p.

Garcia-Ramon, M.-D. (2003). Globalization and international geography: the questions of languages and scholarly traditions. Progress in Human Geography 2 7, 1, 53-69.

Germes, M., Husseini de Araújo, S. (2016). For a critical practice of translation in geography. ACME: an international journal for critical geographies 15 (1), 1-14.

Gomes, P. C. da C. (1996). Geografia e Modernidade. Rio de Janeiro: Bertrand Brasil. 368p.

Gonçalves Barbosa, H., Wyler, L. (2001 [1998]). Brazilian tradition. In: Baker, M. (ed.). Routledge

Encyclopedia of Translation Studies. London and New York: Routledge, 326-333.

Haesbaert, R., Nunes Pereira, S., \& Ribeiro, G. (orgs.). (2012). Vidal, Vidais: textos de Geografia Humana, Regional e Política. Rio de Janeiro: Bertrand Brasil. $464 \mathrm{p}$.

Hanes, W. (2014). Century of Foreign Language in Memórias do Instituto Oswaldo Cruz: Language Policy, Nationalism and Colonial Science. In: Wahab Khalifa, Abdel (Edited by). Translators Have Their Say? Translation and the Power of Agency. Selected Papers of the CETRA Research Summer School 2013. Zurich/Berlin: Lit Verlag, pp.84-110.

Hartshorne, R. (1939). The nature of geography. Annals of the Association of American Geographers, v. 29, No. 3-4, p. 173-658.

Holzer, W. (1998). Um estudo fenomenológico da paisagem e do lugar: a crônica dos viajantes no Brasil do século XVI. USP: Tese de Doutorado. 257p.

Humboldt, A. von., Bonpland, A. (1805). Essai sur la géographie des plantes, accompagné d'un tableau physique des régions équinoxiales. Paris: Levrault, Schoell et Compagnie, Librairies. 157p.

Italiano, F. (2016). Translation and Geography. London and New York: Routledge. 182p.

Italiano, F. (2012). Translating geographies: The Navigatio Sancti Brendani and its Venetian translation. Translation Studies, vol. 5, n.1, 1-16.

Keighren, I. M., Abrahamsson, C., \& della Dora, V. (2012). On canonical geographies. Dialogues in Human Geography 2 (3) 296-312.

Keighren, I. M. (2010). Bringing geography to book. Ellen Semple and the reception of geographical knowledge. London/New York: Taurus. 257p.

Kilomba, G. (2008). Plantation memories. Episodes of everyday racism. Münster: Unrast Verlag. 151pp.

Lacoste, Y. (1988 [1976]). A Geografia 䜿 isso serve, em primeiro lugar, para fazer a guerra. Campinas: Papirus, 263p. Tradução de Maria Cecília França.

Lamego, M. (2020). How International was the International Geographical Congress in Rio de Janeiro 1956? On Location and Language Politics. In: Schellas, B., Ferretti, F., Novaes, A.R., Schmidt di Friedberg, Marcella (Eds.). Decolonising and internationalising geography. Essays in the history of contested science. Cham: Springer International Publishing, p. 113-126.

Lamego, M. (2010). Práticas e representações da geografia quantitativa no Brasil: a formação de uma caricatura. Rio de Janeiro: Tese de Doutorado, PPGG/UFRJ. 247p. 
Latour, B. (1987). Science in action. How to follow scientists and engineers through society. Cambridge, Massachusetts: Harvard University Press. 247pp.

Livingstone, D. N. (2005). Science, text and space: thoughts on the geography of reading, Transactions of the Institute of British Geographers 30, 391-401.

Livingstone, D. N. (2003). A geography of science? In: Livingstone, D. N. Putting science in its place. Geographies of scientific knowledge. Chicago and London: The University of Chicago Press, 1-16.

Lus Bietti, G. (2019). Camille Vallaux. Terra Brasilis 11, 1-20.

Machado, M. S. (2009). A construção da geografia universitária no Rio de Janeiro. Rio de Janeiro: Apicuri. 232pp.

Martins, L. de L. (1992). Friedrich Ratzel: a alteridade de uma geografia. Revista Brasileira de Geografia, 54 (3), jul-set., p.105-113.

Mbembe, A. (2013). Critique de la raison nègre. Paris: La découverte. 224p.

Mendóza, J.G., Jiménez, J.M., Cantero, N.O. (1982). El pensamento geográfico - estudio interpretativo y antología de textos (de Humboldt a las tendencias radicales). Madrid: Alianza Editorial. 530 pp.

Miceli, S. (org). (1989). História das ciências sociais no Brasil - vol. 1. São Paulo: Vértice/IDESP. 490pp.

Minca, C. (2000). Venetian geographical praxis. Society and Space 18, 285-289.

Mignolo, W. (2012). Reflections on translation across colonial epistemic differences. Languages, media and visual imaginary. In: Italiano, F., Rössner, M. (edited by). Translatio/n: Narration, Media and the Staging of Differences. Bielefeld: Transcript Verlag, pp.19-34.

Mignolo, W. (2000). Local histories/global designs: coloniality, subaltern knowledges, and border thinking. Princeton: Princeton University Press. 416pp.

Mignolo, W. (1995). The darker side of the Renaissance. Literacy, territoriality, and colonization. $2^{\text {nd }}$ edition. Michigan: The University of Michigan Press. 463p.

Melgaço, L. (2017). Thinking outside the bubble of the Global North: introducing Milton Santos and "The active role of geography". Antipode, 49 (4), pp.1-6.

Mezzadra, S., Sakai, N. (2014). Introduction. Translation, issue 4 - Politics, spring, 9-29.

Mezzadra, S., Nielson, B. (2013). Border as method, or, the multiplication of labor. Durham and London: Duke University Press. 365pp.

Moraes, A.C.R. (1990). A Antropogeografia de Ratzel: indicações. In: Ratzel, F. (1990). Ratzel. Organização de A.C.R. Moraes. São Paulo: Ática. 199 pp.

Moraes, A.C.R. (1999 [1981]). Geografia: pequena história crítica. 17ª ed. São Paulo: Hucitec. 138pp.

Moreira, R. (2010). o que é geografia? $2^{\underline{a}}$ edição revisada pelo autor. São Paulo: Brasiliense. 71pp.

Moreira, R. (2007). Pensar e ser em geografia. São Paulo: Editora Contexto. 198pp.

Moreira, R. (1980). o que é geografia? São Paulo: Brasiliense. 113pp.

Naylor, S. (2005a). Historical geography: knowledge, in place and on the move, Progress in Human Geography 29, pp.626-634.

Naylor, S. (2005). Introduction: historical geographies of science - places, contexts, cartographies. British Society for the History of Science, march, 38 (1): 1-12.

Nye, J. (2004). Soft power: The means to success in world politics. Nova York: Public Affairs. 208pp. 
Novaes, A. R. (2015). Celebrations and challenges: the international at the 16th International Conference of Historical Geographers, London, July 2015. Journal of Historical Geography, Volume 50, October 2015, 106-108.

Péaud, L. (2019). Alexandre de Humboldt et les acteurs politiques mexicains (1804-1825). La Géographie: terre des Hommes, Société de géographie, pp.34-39.

Pedrosa, B.V. (2013). Entre as ruínas do muro: a história da geografia crítica sob a ótica da ideia de estrutura. USP: Tese de Doutorado, PPGH. 361pp.

Porto-Gonçalves, C.W. (2006). A globalização da natureza e a natureza da globalização. Rio de Janeiro: Civilização Brasileira. 461pp.

Pratt, M.L. (1992). Imperial eyes. Travel writing and transculturation. London and New York: Routledge. 257p.

Quijano, A. (2000). Coloniality of power and social classification. Journal of World-Systems Research 6.2: $342-386$.

Ramicelli, M. E. (2009). Translating cultural paradigms: The role of the Revue Britannique for the first Brazilian fiction writers. In: Milton, J., Bandia, P. (edited by). Agents of translations. Amsterdam/Philadelphia: John Benjamins Publishing Company, 43-61.

Raj, K. (2013). Beyond postcolonialism ... and postpositivism: Circulation and the global history of science. Isis 104:337-347.

Ratzel, F. (1990). Ratzel. Organização de A.C.R. Moraes. São Paulo: Ática. 199p. Tradução de Fátima Murad e Denise Bottman.

Ratzel, F. (2001 [1878]). Viaje de Tehuantepec a Oaxaca. Revista Acervos 23, 27-35.

Ratzel, F. (1983 [1898]). O solo, a sociedade e o Estado. Revista do Departamento de Geografia, 2, 93-101. Tradução de Mário Antônio Eufrásio.

Ribeiro, G. (2020). Nos confins da tradução: deslocamentos de Paul Vidal de la Blache no Brasil (1943-2019). Boletim Goiano de Geografia, v. 40, p. 1-28. Tradução de Guilherme Ribeiro.

Ribeiro, G. (2018). Translation, circulation of knowledge and history of geographical thought: a preliminary study of the Brazilian journals from 1939 to nowadays. 17th International Conference of Historical Geographers, Warsaw.

Ribeiro, G. (2015). Geografia, fronteira do mundo. Ensaio sobre política, epistemologia e história da geografia. Geographia n. 34, 39-73.

Ribeiro, G. (2008). Espaço, tempo e epistemologia no século XX: a geografia na obra de Fernand Braudel. Tese de Doutorado. Niterói: PPGEO, UFF, 382 p.

Robic, M.-C. (2014). La réception de Friedrich Ratzel en France et ses usages au temps de l'installation de la géographie à l'Université (années 1880-1914). Revue germanique internationale, vol.20, 13-39.

Rupke, N. (2000). Translation studies in the history of science: the example of Vestiges. British Journal for the History of Science, 33, 209-222.

Sachs, A. (2003). The Ultimate "Other": Post-Colonialism and Alexander von Humboldt's Ecological Relationship with Nature. History \& Theory, vol. 42, issue 4, pp.111-135.

Sakai, N. (2010). Translation and the figure of border: toward the apprehension of translation as a social action. Profession, 25-34. 
Sakai, N. (1997). Translation and subjectivity. On Japan and cultural nationalism. Minneapolis and London: Minessota University Press. 231p.

Sakai, N. (1992). Voices from the past. The status of language in eighteenth-century japanese discourse. Ithaca and London: Cornell University Press. 349p.

Sanguin, A.-L. (1993). Vidal de la Blache. Un génie de la géographie. Paris: Belin, 384 p.

Santos, M. (2017). Toward an other globalization: from the single thought to universal conscience. London: Springer. Translated and edited by Lucas Melgaço and Tim Clarke. 111pp.

Santos, M. (1999). O dinheiro e o território. GEOgraphia n.1, 7-13.

Santos, M. (1982). Novos rumos para a geografia brasileira. In: Santos, M. (org.). Novos rumos da geografia brasileira. São Paulo: Hucitec, 209-219.

Schaeffer, F.K. (1953). Exceptionalism in geography. A methodological examination. Annals of the Association of American Geographers, 43(3): 226-49.

Schulte, R. (2012). What is translation? Translation Review, 83, 1-4.

Schulte, R. (1992). Translation and the academic world. Translation Review, 38-39:1.

Seerman, J. Mathewson, K. (2011). Herr Ratzel goes to Mexico: colonialism, races, and travel sketches from 1874-1875. Southwestern geographer, v.15, 127-142.

Siebert, L. (2019). Tradução e geografias feministas no IBGE: a atuação da geotradutora de Olga Maria Buarque de Lima Fredrich. Monografia de conclusão de curso. Rio de Janeiro: Departamento de Geografia, UFRRJ. 78pp.

Silva, J.M. (2009). Ausências e silêncios do discurso geográfico brasileiro: uma crítica feminista à geografia eurocêntrica. In: Silva, J.M. (org.). Geografias subversivas: discursos sobre espaço, gênero $e$ sexualidades. Ponta Grossa: TODAPALAVRA, 55-92.

Sodré, N.W. (1976). Introdução à geografia. Geografia e ideologia. Petrópolis: Vozes. 135p.

Sousa, A. N. \& Vaz, C. B. N. (orgs.). (2019). A geografia no alvorecer da República: contribuições à história da ciência geográfica no Brasil. Salvador: EDUFBA. 346p .

Spivak, G. C. (2010). Translating in a world of languages. Profession, pp. 35-43.

Spivak, G. C. (2000). Translation as culture. Parallax, vol. 6, n. 1, 13-24.

Spivak, G. C. (2004 [1993]). The politics of translation. In: Venuti, L. (edited by). Translation Studies Reader. London and New York: Routledge, 397-416.

Suret-Canale, J. (1981). Géographe, marxiste. Espaces temps n. 18/19/20, 9-18.

Thrift, N. (1996 [1994]). Visando o âmago da região. In: Gregory, D., Martin, R., Smith, G. (orgs.). Geografia humana: sociedade, espaço e ciência social. Rio de Janeiro: Jorge Zahar, 215-47. Traduzido por Mylan Isaack.

Tymoczko, M. (2000). Translation and political engagement. Activism, social change and the role of translation in geopolitical shifts. The Translator, vol. 6, n. 1, 23-47.

Velut, S. (2004). Alexander von Humboldt. Entrevista com Aldo Dantas. GEOgraphia, 12, 127-133.

Venuti, L. (2013). Traduire Derrida sur la traduction: relevance et résistance à la discipline. Noesis, 21, 125-129. Translated by René Lemieux.

Venuti, L. (2009). Translation, intertextuality, interpretation. Romance studies, v.27, n.3, july, 157173. 
Venuti, L. (2004). How to read a translation. In: Venuti, L. (ed.). (2013). Translation changes everything. New York: Routledge, 109-115.

Venuti, L. (1998). The Scandals of Translation. London: Routledge. 224 p.

Venuti, L. (1995). The Translator's Invisibility. London: Routledge. 324p.

Vidal de la Blache, P. (1982 [1913]). As características próprias da geografia. In: Christofoletti, A.

(org.). Perspectivas da geografia. São Paulo: Difel, 37-47.

Vidal de la Blache, P. (1897). L'education des indigènes. Revue Scientifique (Revue Rose), n. 12, tome VII, 20 mars, 353-360.

Wulff, A. (2015). The invention of nature: Alexander von Humboldt's new world. Newy York: Knopf Doubleday Publishing Group. 576pp.

\section{ANEXOS}

\section{Anexos}

\section{Traduções (em ordem cronológica)}

Vidal de La Blache, P. (1999). Quadro da Geografia da França (extratos). GEOgraphia, n.1, 141-145. Traduzido do francês por Rogério Haesbaert.

Reclus, E. (1999). O Renascimento. GEOgraphia, n.2, 109-135. Traduzido do espanhol por Ruy Moreira.

Hettner, A. (2000). O sistema das ciências e o lugar da geografia (extratos). GEOgraphia, n.3, 143-146. Traduzido do espanhol por Ruy Moreira.

Sauer, C. O. (2000). A educação de um geógrafo. GEOgraphia, n.4, 137-150. Traduzido do inglês por Werther Holzer.

Ratzel, F. (2001). Amigos, o sublime não mora no espaço. GEOgraphia, n.5, 119-122. Traduzido do alemão por Luciana de Lima Martins com apoio de Ferdinand Reis.

Vidal de La Blache, P. (2001). O princípio da Geografia geral. GEOgraphia, n.6, 135-147. Traduzido do francês por Rogério Haesbaert e Sylvain Souchaud.

Vidal de La Blache, P. (2002). A Geografia Política. A propósito dos escritos de Friedrich Ratzel. GEOgraphia, n.7, 122-137. Traduzido do francês por Rogério Haesbaert e Sylvain Souchaud.

Tricart, J. (2003). A geomorfologia, a edafologia e o ornamento do espaço rural. GEOgraphia, n.9, 135-148. Traduzido do espanhol por Ruy Moreira.

Sorre, M. (2003). A geografia humana (introdução). GEOgraphia, n.10, 137-143. Traduzido do espanhol por Ruy Moreira.

Humboldt, A. von (2004). Considerações sobre os diferentes graus de prazer que oferecem o aspecto da natureza e o estudo de suas leis (extratos). GEOgraphia, n.12, 135-139. Traduzido do espanhol por Sergio Nunes Pereira.

Vidal de La Blache, P. (2005). Os gêneros de vida na geografia humana. Primeiro artigo. GEOgraphia, n. 13, 113-130. Traduzido do francês por Maria Regina Sader e Simone Batista. Revisado por Rogério Haesbaert. 
Reclus, E. (2005). Fragmento de uma viagem a Nova Orleans. GEOgraphia, n. 14, 119-125. Traduzido do francês por Rogério Haesbaert.

Vidal de La Blache, P. (2006). Estradas e caminhos da antiga França. GEOgraphia, n.16, 120-129. Traduzido do francês por Guilherme Ribeiro e Rogério Haesbaert.

Kant, I. (2007). Introdução à geografia física. GEOgraphia, n. 17, 121-129. Traduzido do alemão por Leonardo Arantes. Revisão de Rodrigo Cantu de Souza.

Vidal de La Blache, P. (2007). As condições geográficas dos fatos sociais. GEOgraphia, n. 18, 123-132. Traduzido do francês por Guilherme Ribeiro. Revisão de Rogério Haesbaert.

Benjamin, W. (2008). O terremoto de Lisboa. GEOgraphia, n. 19, 111-115. Traduzido do alemão por Leonardo Arantes. Revisão de Rodrigo Cantu de Souza, Stefanie Vogl e Martin Maier. Revisão final de Rogério Haesbaert.

Kant, I. (2008). Projeto e Anúncio da Geografia Física. GEOgraphia, n. 19, 117-123. Traduzido do alemão por Leonardo Arantes. Revisão de Rodrigo Cantu de Souza, Stefanie Vogl e Martin Maier. Revisão final de Rogério Haesbaert.

Vidal de La Blache, P. (2008). Lição de abertura do curso de geografia. GEOgraphia, n. 20, 124-131. Traduzido do francês por Guilherme Ribeiro. Revisão de Rogério Haesbaert.

Dresch, J. (2009). o declínio do colonialismo. GEOgraphia, n. 21, 180-188. Traduzido do francês por Breno Viotto Pedrosa.

Vidal de La Blache, P. (2009). Estados e nações da Europa em torno da França (extratos). GEOgraphia, n. 22, 133-153. Traduzido do francês por Rogério Haesbaert.

Ratzel, F. (2010). Sobre a interpretação da natureza. GEOgraphia, n. 23, 157-176. Traduzido do alemão por Marcos Bernardino de Carvalho a partir de esboço parcial feito por Mara Sandra Zanin. Revisão Técnica: Wolf Dietrich-Sahr.

Reclus, E. (2010) Crônica geográfica. GEOgraphia, n.24, 166-168. Traduzido do francês por Rogério Haesbaert.

Hettner, A. (2011). A geografia como ciência corológica da superfície terrestre. GEOgraphia, n. 25, 136-152. Traduzido do alemão por Leonardo Arantes com apoio de Wolf Dietrich-Sahr.

Hettner, A. (2011) A essência e as tarefas da geografia. GEOgraphia, n.26, 136-149. Traduzido do alemão por Leonardo Arantes.

Hettner, A. (2012). Os ramos da geografia e sua relação com as ciências da natureza. GEOgraphia, n. 28, 138-160. Traduzido do alemão por Leonardo Arantes. Revisão de Rogério Haesbaert.

George, P. (2013). Varsóvia 1949: reconstrução ou nascimento de uma nova cidade? GEOgraphia, n. 29, 118-134. Traduzido do francês por Breno Viotto Pedrosa.

Hettner, A. (2013). A geografia estética e a geografia como arte. GEOgraphia, n. 30, 144-152. Traduzido do alemão por Leonardo Arantes.

Hettner, A. (2013). A geografia prática. GEOgraphia, n. 30, 153-160. Traduzido do alemão por Leonardo Arantes.

Hettner, A. (2013). O valor estético da paisagem. GEOgraphia, n. 30, 161-167. Traduzido do alemão por Leonardo Arantes. 
Hettner, A. (2013). O valor prático da paisagem. GEOgraphia, n. 30, 168-171. Traduzido do alemão por Leonardo Arantes.

Mackinder, H. J. (2014). O ensino de geografia sob a ótica imperial e os usos que podem e devem ser feitos da instrução visual. GEOgraphia, n. 31, 142-152. Traduzido do inglês por Guilherme Ribeiro e Leroy Honorio Azevedo.

Kropotkin, P. (2014). As guerras e o capitalismo. GEOgraphia, n. 32, 174-190. Traduzido do inglês por Amir El-Hakim de Paula.

Sochava, V.B. (2015) El objeto de la geografia física a la luz de la teoria de los geossistemas. GEOgraphia, n. 33, 234-244. Traduzido do russo por José Mateo, Edson Vicente da Silva, Raúl Sánchez Vicens.

Ronai, M. (2015). Paisagens II. GEOgraphia, n. 34, 247-261. Traduzido do francês por Werther Holzer.

Vallaux, C. (2015). As aspirações regionalistas e a geografia. GEOgraphia, n. 35, 204-215. Traduzido do francês por Willian Moraes Antunes de Sousa, Rogério Haesbaert e Juliana Nunes Rodrigues.

Ritter, C. (2016). Algumas observações sobre o ensino metódico na geografia. GEOgraphia, n. 36, 212-226. Traduzido do alemão por Leonardo Arantes. Revisão de WolfDietrich Sahr.

Ratzel, F. (2016). Geografia política (prefácio da primeira e da segunda edição). GEOgraphia, n. 37, 233-236. Traduzido do alemão por Marquessuel Dantas de Souza e Gabriel Reichenheim. Revisão: Leonardo Arantes.

Humboldt, A. von. (2016). Eu sobre mim mesmo (Meu percurso até me tornar naturalista e viajante-pesquisador [1769-1790]). GEOgraphia, n. 38, 168-172. Traduzido do alemão por Leonardo Arantes.

Humboldt, A. von. (2016). Julgamento fundamental acerca do sistema colonial. GEOgraphia, n. 38, 173-176. Traduzido do alemão por Leonardo Arantes.

Vallaux, C. (2017). Sobre "Princípios de geografia humana" de Paul Vidal de la Blache, "A terra e a evolução humana" de Lucien Febvre e "A vida pastoril nos Alpes Franceses", de Philippe Arbos. GEOgraphia, n. 39, 100-102. Traduzido do francês por Willian Moraes Antunes de Sousa.

Santos, M. (2017). Subimperialismo, na visão de um geógrafo. GEOgraphia, n. 40, 180-184. Traduzido do inglês por Thiago Machado.

Lefebvre, H. (2017). Problemas teóricos da autogestão. GEOgraphia, n. 41, 135-141. Traduzido do inglês por Maria Lucia Oliveira. Revisão técnica: Rogério Haesbaert.

Kropotkin, P. (2018). A descentralização da indústria. GEOgraphia, n. 42, 116-119. Traduzido do inglês por Rodolpho Jordano Netto, Rogério Haesbaert e Daniel Sanfelici.

Ritter, C. (2018). Sobre o elemento histórico na ciência geográfica. GEOgraphia, n. 42, 142-155. Traduzido do alemão por Leonardo Arantes.

Reclus, E. (2018). O patriotismo é incompatível com o amor pela humanidade? GEOgraphia, n. 44, 113-114. Traduzido do francês por Rogério Haesbaert. 
Ratzel, F. (2019). O espaço da vida: um estudo biogeográfico. GEOgraphia, n. 45, 107-116. Traduzido do alemão por Leonardo Arantes. Revisão de Rogério Haesbaert.

Ratzel, F. (2019). 0 espaço da vida: um estudo biogeográfico. Parte II. GEOgraphia, n. 46, 120-130. Traduzido do alemão por Leonardo Arantes. Revisão de Rogério Haesbaert.

Ratzel, F. (2019). O espaço da vida: um estudo biogeográfico. Parte III. GEOgraphia, n. 47, 115-129. Traduzido do alemão por Leonardo Arantes. Revisão de Rogério Haesbaert.

\section{Comentários às traduções (em ordem cronológica)}

Haesbaert, R. (1999). Paul Vidal de la Blache. GEOgraphia, n.1, 139-140

Moreira, R. (1999). Élisée Reclus (1830-1905). GEOgraphia, n.2, 107-108.

Moreira, R. (2000). Alfred Hettner (1859-1941). GEOgraphia, n.3, 141-142.

Holzer, W. (2000). Carl Sauer (1889-1975). GEOgraphia, n.4, 135-136.

Martins, L. de L. (2001). Friedrich Ratzel. GEOgraphia, n.5, 115-117.

Haesbaert, R. (2001). Paul Vidal de la Blache. GEOgraphia, n.6, 133.

Haesbaert, R. (2002). La Blache, Ratzel e a "Geografia Política”. GEOgraphia, n.7, 117-121.

Moreira, R. (2003). Jean Tricart. GEOgraphia, n.9, 133-134.

Moreira, R. (2003). Max Sorre. GEOgraphia, n.10, 135-136.

Moreira, R. (2004). Pierre Monbeig. GEOgraphia, n.11, 107-108.

Haesbaert, R. (2005). Élisée Reclus (1830-1905). GEOgraphia, n.14, 113-118.

Severo, R.P. (2006). Immanuel Kant (1724-1804). GEOgraphia, n.15, 129-130.

Ribeiro, G. (2006). A Geografia Humana vidaliana e a ciência moderna em finais do século XIX e início do XX. GEOgraphia, n. 16, p. 117-119.

Arantes, L. (2007). Immanuel Kant (1724-1804). GEOgraphia, n.17, 117-119.

Ribeiro, G. (2007). Uma epistemologia em construção. Diálogos entre a Geografia e a Sociologia em Paul Vidal de la Blache. GEOgraphia, n. 18, p. 117-122.

Arantes, L. (2008). Immanuel Kant (1724-1804) e Walter Benjamin (1892-1940). GEOgraphia, n.19, 107-109.

Ribeiro, G. (2008). Para além da ingenuidade: releituras vidalianas. GEOgraphia, n. 20, p. 124-131.

Pedrosa, B. (2009). O retrato do imperialismo em metamorfose na obra de Jean Dresch. GEOgraphia, n. 21, 176-179

Haesbaert, R. (2009). "Estados e Nações": Vidal no cruzamento entre as dimensões política e cultural da Geografia. GEOgraphia, n. 22, p. 128-131.

Carvalho, M.B. de. (2010). Friedrich Ratzel (1844-1904): “O insípido está sempre incorreto". GEOgraphia, n. 23, p. 140-153.

Sahr, W.-D. (2010). Comentário sobre o nosso triálogo entre texto, tradução e revisão. GEOgraphia, n. 23, p. 154-156.

Sahr, W.-D., Arantes, L. (2011). A profusão das teorias espaciais e a fusão do espaço geográfico: Alfred Hettner e o projeto corológico. GEOgraphia, n. 25, p. 106-135. 
Arantes, L. (2012). Alexander von Humboldt, sua Weltanschauung e a Fundação da Geografia Moderna. GEOgraphia, n. 27, 126-128.

Pedrosa, B. (2013). Pierre George, um ilustre desconhecido. GEOgraphia, n. 29, 99-117.

Arantes, L., Sahr, W.-D. (2013). Geografia: entre a ciência, a arte e a práxis. GEOgraphia, n.30, 141-143.

Ribeiro, G. (2014). Geografias imperiais: o caso de Halford John Mackinder (1861-1947). GEOgraphia, n. 31, p. 153-169.

El-Hakin de Paula, A. (2014). Piotr Kropotkin. GEOgraphia, n.32, 171-173.

Rodríguez, J.M.M., Silva, E.V. da., Vicens, R.S. (2015). O legado de Sochava. GEOgraphia, n. 33, 225-233.

Holzer, W. (2015). Breve biografia de Maurice Ronai. GEOgraphia, n. 34, 262-263.

Sousa, W. M. A. de (2015). Camille Vallaux: uma figura da geografia clássica francesa. GEOgraphia, n.35, 197-203.

Arantes, L. (2016). Carl Ritter: educador e geógrafo. GEOgraphia, n.36, 207-212.

Arantes, L. (2016). Alexander von Humboldt. GEOgraphia, n.38, 164-166.

Sousa, W. M. A. de (2017). Um modelo de resenha por Camille Vallaux: uma figura da geografia clássica francesa. GEOgraphia, n.39, 95-102.

Machado, T. (2017). Geografia e dependência: o diálogo entre Milton Santos e Ruy Mauro Marini a partir da teoria do subimperialismo. GEOgraphia, n.40, 185-190.

Jordano Netto, R. (2018). Piotr Kropotkin: breve introdução ao autor. GEOgraphia, n.42, 115.

Arantes, L. (2018). Da "geografia da modernidade" à "modernidade da geografia": a aniquilação do espaço pelo tempo e o projeto ritteriano de uma geografia "mais" científica. GEOgraphia, n.43, 136-141.

\section{NOTAS}

1. Seus arquivos estão disponíveis em: <https://periodicos.uff.br/geographia/issue/archive>.

2. Baseado em sua experiência como professor e gestor nas últimas décadas na Universidade Federal do Ceará (UFC) e na CAPES, Eustógio Dantas compartilhou conosco essa interpretação por telefone em 27 de fevereiro de 2021. Nós a subscrevemos integralmente.

3. Informações referentes à formação dos geotradutores foram encontradas em seus respectivos currículos lattes: <http://buscatextual.cnpq.br/buscatextual/busca.do?metodo=apresentar>.

4. O impacto dos alemães sobre a Escola Francesa de Geografia foi estudado por Broc (1977) e Berdoulay (1995 [1981]).

5. As obras dos geógrafos anarquistas por ele traduzidas estão disponível em: < https:// bibliotecaterralivre.noblogs.org/>.

6. Parece que os leitores mais jovens não atentaram para o prefácio à $14^{\mathrm{a}}$ edição do Pequena história crítica assinado pelo próprio autor em 1995, reconhecendo seu livro como "obra datada que fornece informação histórica, mas não orienta para o presente” (Moraes, 1999: 9). Já o que é geografia? ganhou nova edição em 2010 e, a confiarmos no autor, "difere substancialmente da 
anterior. A primeira metade foi inteiramente reescrita. Mantivemos seu cunho de um breve resumo histórico do pensamento geográfico (...) (Moreira, 2010: 7)".

7. Muito embora sejam bastante instrutivas as notas linguísticas redigidas sobretudo por Arantes, bem como a pérola de clareza e generosidade anotada por Sahr sobre sua revisão da tradução de Ratzel por Carvalho (Sahr, 2010).

\section{RESUMOS}

Desde sua primeira edição em 1999, a revista brasileira GEOgraphia tem publicado a seção Nossos Clássicos. Composta por material estrangeiro traduzido para a língua portuguesa e acompanhado de comentários críticos redigidos pelos próprios tradutores, esse material ainda não foi estudado, pois a tradução tem sido ignorada como tema de pesquisa pelos geógrafos brasileiros e pela Academia como um todo. Articulando pensamento decolonial e translation studies como referências metodológicas, constatamos que em um país periférico como o Brasil, onde ciência e tradução estão intimamente associadas por causa da geopolítica do conhecimento, tradutores têm exercido papel fundamental como agentes tanto da circulação do conhecimento em geral quanto da renovação da história da geografia em particular ao problematizar determinados cânones que a constituíram. Assim, no período entre 1999 e 2019, graças ao trabalho do que denominaremos por geotradutores, a seção Nossos Clássicos tornou-se fonte privilegiada de leitura e discussão sobre a história da geografia produzida no Brasil e no exterior. O presente artigo visa reconhecer quem são esses geotradutores e quais são suas motivações a fim de iluminar a circulação dos clássicos em um país periférico como o Brasil.

Ever since its first edition in 1999, the Brazilian journal GEOgraphia has been publishing a section called Nossos Clássicos [Our Classics]. Made up of foreign-language texts translated into Portuguese, and associated commentaries done by translators themselves, this material has not yet been studied because translation is still overlooked by both Brazilian geographers and scholars in general as a subject of research. Linking translation studies and decolonial thought as methodological resources, I suggest that in a peripheral country such as Brazil, where translation and science are intimately interwoven thanks to the geopolitics of knowledge, translators have had a crucial role as agents both of the circulation of knowledge and the interrogation of canonical geographies at international and national levels concomitantly. So I name those responsible for the Our Classics rubric geotranslators, and in the period 1999-2019 my aim is to study who are they, who they translated and for what reasons they do this. In doing so, I will shed some light on the circulation of classics in a peripheral country such as Brazil.

Dès son premier numéro en 1999, la revue Brésilienne GEOgraphia publie une section appellée Nossos Clássicos [Nos Classiques]. Composée d'articles étrangers traduits vers le Portugais, ainsi que de commentaires rédigés par les traducteurs eux-mêmes, ce dossier n'a pas encore été étudié parce que si les géographes Brésiliens que les académiques en générale ont dévalorisé la traduction en tant que sujet de recherche. En articulant les translation studies et la pensée décoloniale en termes de méthode, j'indique que dans un pays périphérique comme le Brésil la traduction et la science sont intimement liées à cause de la géopolitique de la connaissance. Par conséquence, les traducteurs ont eu un role crucial en tant qu'agents de la circulation scientifique et de la critique aux géographies canoniques nationales et internationales à la fois. 
Ainsi, je pense qu'il faut les nommer géotraducteurs. En étudiant la période 1999-2019, le but de cet article est de savoir qu'ils sont, pourquoi ils se sont lancés vers ce genre de travail et qui sont les auteurs traduits. De ce fait, on a la chance d'éclaircir la dynamique de la circulation de classiques dans un pays périphérique comme le Brésil.

Desde su primera edición en 1999, la revista brasileña GEOgraphia publica la sección Nuestros Clásicos. Compuesto por material extranjero traducido al portugués y acompañado de comentarios críticos escritos por los propios traductores, este material aún no ha sido estudiado, ya que la traducción ha sido ignorada como tema de investigación por los geógrafos brasileños y por la Academia en su conjunto. Vinculando el pensamiento descolonial y los estudios de traducción como referentes metodológicos, encontramos que en un país periférico como Brasil, donde ciencia y traducción están estrechamente asociadas debido a la geopolítica del conocimiento, los traductores han jugado un papel fundamental como agentes tanto de la circulación del conocimiento en general y la renovación de la historia de la geografía, en particular, problematizando ciertos cánones que la constituían. Así, en el período comprendido entre 1999 y 2019, gracias al trabajo de los que llamaremos geotraductores, la sección Nuestros Clásicos se convirtió en una fuente privilegiada para leer y discutir la historia de la geografía producida en Brasil y en el exterior. Este artículo tiene como objetivo reconocer quiénes son estos geotraductores y cuáles son sus motivaciones para iluminar la circulación de clásicos en un país periférico como Brasil.

\section{ÍNDICE}

Índice geográfico: Brasil

Palavras-chave: translation studies, circulação de clássicos na periferia, geopolíticas do conhecimento, geografias canônicas, história da geografia

Palabras claves: translation studies, circulación de clásicos en la periferia, geopolítica del conocimiento, geografías canónicas, historia de la geografía

Keywords: translation studies, circulation of classics in the periphery, geopolitics of knowledge, canonical geographies, history of geography

Mots-clés: translation studies, circulation périphérique des classiques, géopolitique de la connaissance, géographies canoniques, histoire de la géographie

Índice cronológico: Século XX, Século XXI

\section{AUTOR}

\section{GUILHERME RIBEIRO}

Universidade Federal Rural do Rio de Janeiro, Departamento de Geografia, Programa de PósGraduação em Geografia, Laboratório Política, Epistemologia e História da Geografia (UFRRJ/ DGG/PPGGEO/LAPEHGE). E-mail: lapehge@gmail.com 